This peer reviewed manuscript has been accepted for publications to the Wear.

Cite this article as: S. Matkovič, M. Kalin, Effects of slide-to-roll ratio and temperature on the tribological behaviour in polymer-steel contacts and a comparison with the performance of realscale gears, Wear (2021) 477: 203789. DOI: https://doi.org/10.1016/j.wear.2021.203789.

CC BY-NC-ND

\title{
Effects of slide-to-roll ratio and temperature on the tribological behaviour in polymer-steel contacts and a comparison with the performance of real-scale gears
}

\author{
S. Matkovič, M. Kalin* \\ Laboratory for Tribology and Interface Nanotechnology, Faculty of Mechanical Engineering, \\ University of Ljubljana, Bogisiceva 8, 1000 Ljubljana, Slovenia \\ *corresponding author: mitjan.kalin@tint.fs.uni-lj.si
}

\begin{abstract}
Gearboxes that employ polymer gears are being used in an ever-increasing number of different applications. However, polymer-gear design suffers from a lack of understanding of their tribological behaviour under controlled - but at the same time realistic - conditions. One of the factors that is often overlooked in model tribological tests is the effect of the slide-to-roll ratio (SRR), which is different in gear meshing and conventionally used model tribological experiments with pure sliding. In this study, we analyse the wear mechanisms and wear coefficients, as well as the friction, in very common gear pairs of non-lubricated POM/steel contacts, but at different SRRs (25 to $150 \%)$ and at two controlled temperatures $\left(50\right.$ and $\left.80{ }^{\circ} \mathrm{C}\right)$. The load was also varied (8 and $45 \mathrm{~N}$ ). The results show that tests at $50{ }^{\circ} \mathrm{C}$ in SRR-variable model tribotests can predict the SRRdependent wear mechanisms along the meshing path (positions A-E) in real gears, while the $80{ }^{\circ} \mathrm{C}$ tests are too severe, leading to thermal overload. An about 10-times-larger wear coefficient, compared to the gear tests, was measured during our SRR-variable tests, which is a better estimation compared to the common pin-on-disc test with 2-4 orders-of-magnitude deviation. Furthermore, based on an accurate simulation of the friction behaviour in model tribotests, compared to gear tests, an empirical model based on tribological tests with a variable SRR was developed that predicts the coefficient of friction along the meshing contact line in real-scale gears with a 3\% deviation. This study shows that the SRR- and temperature-controlled model tribological tests are relevant for understanding the real-scale polymer gears' tribological behaviour and mechanisms and furthermore they generate predictive, empirical results.
\end{abstract}

Key words: polymer, POM, steel, gear, slide-to-roll ratio (SRR), wear, friction 
This peer reviewed manuscript has been accepted for publications to the Wear.

Cite this article as: S. Matkovič, M. Kalin, Effects of slide-to-roll ratio and temperature on the tribological behaviour in polymer-steel contacts and a comparison with the performance of realscale gears, Wear (2021) 477: 203789. DOI: https://doi.org/10.1016/j.wear.2021.203789.

\section{BY-NC-ND}

\section{Introduction}

Mechanical elements such as gears and bearings made from polymers are used in numerous demanding applications where accurate design calculations must be performed to ensure a sufficient lifetime of the elements. However, to be able to use lifetime-prediction methods and design-calculation equations, the tribological behaviour, i.e., the coefficient of friction, wear coefficient and wear mechanisms of the materials in contact, must be known.

The two most common materials for these elements are polyamides (PA) and polyacetals (POM), together with other high-performance polymer materials such as PBT, PEEK, and PPS [1]. The benefits of using polymer gears are their low weight, ease of manufacture, design freedom, as well as low cost, low noise and low vibration. In addition, polymer gears can operate without lubrication. These benefits derive from the very different material properties compared to metals [2]. The main difference is the Young's modulus, which can be as much as one hundred times lower than those of steels [3]. Additionally, the Young's modulus of polymers can vary significantly with temperature. Another drawback is the thermal conductivity of polymers, which is much lower than that of the steel $(\sim 100 \times)$ [3]. This results in increased operating temperatures, since the heat generated by the friction is not quickly removed from the teeth [4,5]. As a result, permanent deformation, and in some severe cases even melting, of the teeth occur, which is not a common occurrence in metal gears. Accordingly, to minimize the chance of thermal failure, a metal pinion is often selected to pair with a polymer gear; this better dissipates the heat from the contact surfaces than when two polymer gears are meshing.

Due to the involute geometry of cylindrical gears, which are the most common type, the forces, sliding velocities and slide-to-roll ratios vary along the point of contact [6]. This point of contact is typically characterized by five different points: point $\mathrm{A}$, the point of first contact; point $\mathrm{B}$, the highest point of single contact; point $\mathrm{C}$, the kinematic point at which theoretically there is no sliding and therefore the coefficient of friction is the lowest; point $\mathrm{D}$, the lowest point of singletooth contact; and point $\mathrm{E}$, the last point of contact. Due to the variation in the contact conditions with the gears, a detailed model tribological study is a challenge.

Model tribological tests such as the pin-on-disc are very common for studying the tribological behaviour of polymers; however, those tests only enable the study of pure sliding conditions, which is not realistic for gear meshing. Nevertheless, these studies found that the tribological properties of polymers are influenced by the roughness of the metal counter body, the sliding velocity, contact pressure, material combinations, temperature, etc. [7-15]. 
This peer reviewed manuscript has been accepted for publications to the Wear.

Cite this article as: S. Matkovič, M. Kalin, Effects of slide-to-roll ratio and temperature on the tribological behaviour in polymer-steel contacts and a comparison with the performance of realscale gears, Wear (2021) 477: 203789. DOI: https://doi.org/10.1016/j.wear.2021.203789.

\section{BY-NC-ND}

Some authors tried to model real-scale polymer-gear contacts more realistically than the pin-ondisc configuration, by using a twin-disc apparatus, which enables a variation of the SRR [16-18]. Kukureka et al. [19] conducted a detailed investigation of POM/POM contacts, where they found two regions with different wear rates. Firstly, the mild wear rate, where the wear is independent of the rolling speed and the slip ratio and varies with the peak Hertzian contact stress. While in the severe wear region, high temperatures arise due to frictional heating, which caused lateral cracking of the surface and subsequent tearing.

However, it should be noted that in real applications, especially in the most relevant highperformance contacts, POM is used against steel, rather than self-mated with POM, as investigated in [19]. Another drawback of the twin-disc model tribological apparatus is that there is a limitation on the maximum variation of the SRR, which tends to be at around 30\%, whereas slip ratios above $30 \%$ are normally found in the gear meshing [20]. In addition, with twin discs, the slip and roll components of the contact velocity are in the same direction, while in real gears, the roll and slip are in opposing directions [21]. Due to these deficiencies associated with twin discs, we propose a study of the tribological properties using a ball-on-disc test apparatus with a much higher SRR variation, which was shown to be a valid test for mimicking steel gears [22].

Another important topic also needs to be addressed. Namely, a recent study of Evans and Keogh [21] proposed smearing as a new wear mechanism for POM gears in contact with steel pinons. A phenomenological model was presented, describing how smearing is initiated, formed and developed and is based on the slip/roll characterization of the involute spur gear. This was a worthy attempt to understand the effect of slip-to-roll conditions in the gear contacts; however, only one torque and one speed were used, which prevented a more profound parametric understanding. Moreover, the temperatures of the gears were not constant during the tests, which is essential to understanding the behaviours of the polymers, as shown by the huge effect on the behaviour of polymer gears by Kalin and Kupec [23].

Accordingly, in this study we present tribological analyses of a model tribological test, where POM balls were in contact with a steel disc under various SRRs, aiming to produce more realistic conditions while maintaining a constant, pre-selected temperature of the polymer material. Tests were conducted at two different temperatures and normal loads, and for several different slide-toroll ratios. The wear coefficients and wear mechanisms were determined from the model tests and were compared to real-scale gear tests performed under conditions that were as similar as possible to the model tests. Furthermore, analyses of the coefficient of friction from the tribological and gear tests allowed us to develop a model that accurately predicts the coefficient of friction along the meshing contact line in real-scale gears based on model tribological tests with a variable SRR.

\section{Experimental}


This peer reviewed manuscript has been accepted for publications to the Wear.

Cite this article as: S. Matkovič, M. Kalin, Effects of slide-to-roll ratio and temperature on the tribological behaviour in polymer-steel contacts and a comparison with the performance of realscale gears, Wear (2021) 477: 203789. DOI: https://doi.org/10.1016/j.wear.2021.203789.

\section{BY-NC-ND}

\subsection{Materials and specimens}

The samples used for the tribological evaluation were standard, mini-traction machine (MTM) test specimens that allow a slide-to-roll ratio (SRR) variation. The samples used were polymer balls machined from polyacetal Delrin 500P (DuPont, Germany) with a diameter of $19.05 \mathrm{~mm}$ and a Rockwell M hardness of $92 \mathrm{MPa}$. Discs of 100Cr6 steel with a diameter of $46 \mathrm{~mm}$, a thickness of $6 \mathrm{~mm}$ and a hardness of $62 \mathrm{HRC}$ were used as the lower-disc samples. The roughness of the polymer balls was $R_{\mathrm{a}}=0.5 \mu \mathrm{m}$ (as received), while the disc roughness was $R_{a}=0.2 \mu \mathrm{m}$, measured for verification prior to the tests with a stylus-tip profilometer (T8000 Hommelwerke, Schwenningen, Germany) in a various directions. Both the balls and discs were supplied by PCS Instruments (London, UK).

The second type of samples were the gears for the real-scale gear tests. A common, commercial pair of steel pinion versus polymer gears was studied. The steel gears with a hardness of $62 \mathrm{HRC}$ were produced by machining. The surface roughness of the pinon flank was the same as the surface roughness of the MTM steel discs $\left(R_{a}=0.2 \mu \mathrm{m}\right)$. Overall, a pinon quality of 6 , according to ISO 1328 [24], was achieved. The polymer gears were injection moulded from polyacetal Delrin 500P, the same as the ball for the MTM tribotests, produced using a no-weld injection-moulding technology. Their roughness was $R_{\mathrm{a}}=0.5 \mu \mathrm{m}$. A quality of 10 , according to ISO 1328 [24], was achieved.

The material properties of the steel and the polymer samples for the tribological tests with a variable SRR and real-scale gear tests, which has the same characteristics, are summarised in Table 1 .

Table 1: Basic properties of the test materials.

\begin{tabular}{|l|l|l|}
\hline & Polymer MTM ball, polymer gear & Steel MTM disc, steel pinion \\
\hline Material & POM - Delrin 500P & Steel - 100Cr6 \\
\hline Density $[\mathrm{g} / \mathrm{cm}]$ & 1.41 & 7.65 \\
\hline Elastic modulus at $50^{\circ} \mathrm{C}[\mathrm{GPa}]$ & 2.25 & 210 \\
\hline Elastic modulus at $80^{\circ} \mathrm{C}[\mathrm{GPa}]$ & 1.37 & 210 \\
\hline Hardness & $\begin{array}{l}\text { Rockwell M92 } \mathrm{MPa}^{*} \\
\text { Rockwell R120 MPa* }\end{array}$ & $62 \mathrm{HRC}$ \\
\hline Poisson's Ratio & 0.37 & 0.29 \\
\hline
\end{tabular}

*Test method ISO $2039(\mathrm{R}+\mathrm{M})$ [25].

\subsection{Tribological tests}


This peer reviewed manuscript has been accepted for publications to the Wear.

Cite this article as: S. Matkovič, M. Kalin, Effects of slide-to-roll ratio and temperature on the tribological behaviour in polymer-steel contacts and a comparison with the performance of realscale gears, Wear (2021) 477: 203789. DOI: https://doi.org/10.1016/j.wear.2021.203789.

CC BY-NC-ND

The tribological tests were performed using a ball-on-disc, mini-traction machine MTM (PCS Instruments, UK) with a variable SRR under non-lubricated conditions, common for many polymer-gear applications. The variable-SRR tribotester (i.e., the MTM) was in-house upgraded from a standard version with components for the regulation of the polymer specimen's temperature: an infrared camera (Optris PI160, Optris GmbH, Germany), an electromagnetic valve for controlling the compressed cooling air and an additional air filter. The measurement area of the infrared camera ( $4 \times 3$ pixels) was set on the path of contact of the polymer ball, where the mean temperature was monitored (Fig. 1a). Before the tribological evaluation, the emissivity was calibrated using a thermocouple and a heating element. The PID regulation was controlled using LabView software and a DAQ NI system. The material was heated with a pre-installed pot heater.

With these upgrades, all the tribological tests were performed under constant polymer-surface temperatures of $50 \pm 2{ }^{\circ} \mathrm{C}$ and $80 \pm 2{ }^{\circ} \mathrm{C}$, controlled on the polymer material, as shown in Fig. $1 \mathrm{~b}$. Therefore, changes in the contact conditions due to frictional heating were prevented, which enabled an evaluation of the tribological behaviour due to variations of the SRR only, without any simultaneous change in the surface temperature, which would otherwise be expected. This also allowed a direct comparison of the SRR-variable tribological tests with real-scale gear tests, where the controlled and fixed gear temperatures were required to compare the wear and fatigue performance of the various gear materials $[23,26]$.

The tribological evaluation was performed under two different normal loads, i.e., $8 \mathrm{~N}$ and $45 \mathrm{~N}$. The corresponding maximum Hertzian contact pressure was 50/90 $\mathrm{MPa}$ at $50{ }^{\circ} \mathrm{C}$ and $30 / 60 \mathrm{MPa}$ at $80{ }^{\circ} \mathrm{C}$, at $8 / 45 \mathrm{~N}$, respectively. The values for the mean Hertzian contact pressure were 30/60 $\mathrm{MPa}$ for tests conducted at $50{ }^{\circ} \mathrm{C}$ and $20 / 40 \mathrm{MPa}$ for $80^{\circ} \mathrm{C}$. During all the tests, the entrainment velocity $v_{\mathrm{e}}$ was constant at $370 \mathrm{~mm} / \mathrm{s}$, which was selected to comply with many polymer-gear drives, while the sliding velocity changed to obtain different SRR values. The SRR ratios were calculated according to eq. 1 , where $v_{\mathrm{s}}$ is sliding velocity and $v_{\mathrm{e}}$ entrainment velocity, meaning that for pure rolling the SRR was 0 and for pure sliding the SRR was $200 \%$. 
This peer reviewed manuscript has been accepted for publications to the Wear.

Cite this article as: S. Matkovič, M. Kalin, Effects of slide-to-roll ratio and temperature on the tribological behaviour in polymer-steel contacts and a comparison with the performance of realscale gears, Wear (2021) 477: 203789. DOI: https://doi.org/10.1016/j.wear.2021.203789.

\section{BY-NC-ND}
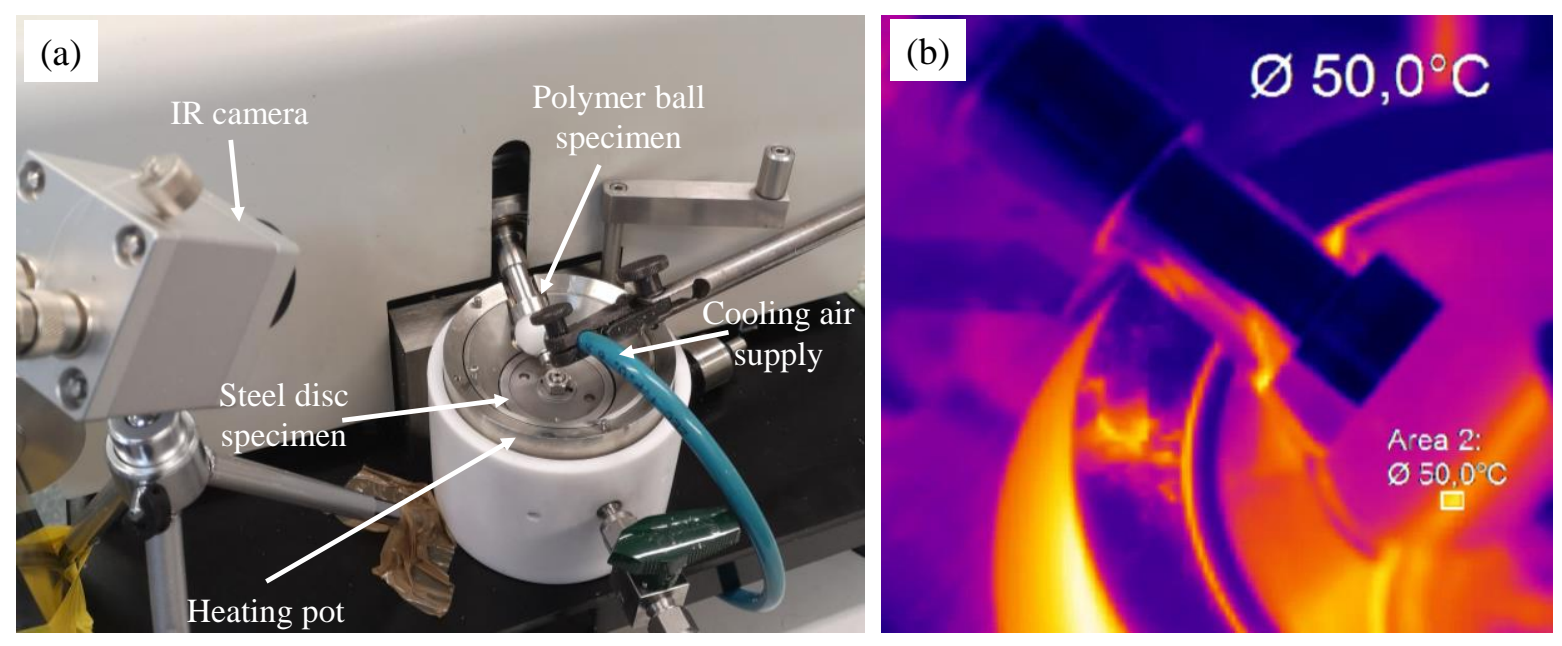

Fig. 1: (a) SRR-variable tribological test configuration; (b) thermographic images of polymer ball.

Two different types of tribological tests were performed. The first test type was designed to obtain the coefficient of friction at different SRRs for both temperatures and both loads, i.e., $50 / 80{ }^{\circ} \mathrm{C}$ and $8 / 45 \mathrm{~N}$. The SRRs were varied from 0 to $150 \%$ with a step of $25 \%$, see Table 2 . The duration of each step was $20 \mathrm{~min}$. Each step started with pure rolling $(\mathrm{SRR}=0 \%)$ to severe sliding $(\mathrm{SRR}=150 \%)$. At the end of each test the pure-rolling test was performed once again to verify the validity and variation of the results due to possible sliding-induced damage and surface changes during the test.

$\operatorname{SRR}=\frac{v_{\mathrm{s}}}{v_{\mathrm{e}}}=\frac{v_{\text {ball }}-v_{\text {disc }}}{v_{\mathrm{e}}}$

The second type of test was conducted to investigate the influence of temperature, load and SRR on the wear mechanisms and the corresponding wear coefficient on selected samples with distinctive surface conditions. Therefore, the tests were performed at both temperatures and both loads, i.e., $50 / 80{ }^{\circ} \mathrm{C}$ and $8 / 45 \mathrm{~N}$, while the SRR was selected to have a constant value of $50 \%$, a typical value for real-scale gear meshing. Additionally, to systematically evaluate the influence of the SRR, the tests were made at 50,100 and 150\% for both temperatures, while the load was kept constant at $45 \mathrm{~N}$ in these tests.

The wear of the polymer balls was evaluated by measuring the weight on an analytical scale (XA 210/ X, Radwag, Poland) with a precision of $10^{-5} \mathrm{~g}$ and dividing it by the density of the polymer to obtain the wear volume. The effects of humidity and running-in were always evaluated and considered, as explained later. After the wear volume was obtained, the wear coefficients were 
This peer reviewed manuscript has been accepted for publications to the Wear.

Cite this article as: S. Matkovič, M. Kalin, Effects of slide-to-roll ratio and temperature on the tribological behaviour in polymer-steel contacts and a comparison with the performance of realscale gears, Wear (2021) 477: 203789. DOI: https://doi.org/10.1016/j.wear.2021.203789.

\section{BY-NC-ND}

calculated using eq. 2 . The sliding distance was calculated by multiplying the sliding velocity (from Table 2) by the time of the test.

Table 2: Slide-to-roll ratios and corresponding velocities for the tribological evaluation.

\begin{tabular}{|c|c|c|c|}
\hline $\begin{array}{c}\text { SRR } \\
{[\%]}\end{array}$ & $\begin{array}{c}\text { Sliding velocity } \\
{[\mathrm{mm} / \mathrm{s}]}\end{array}$ & $\begin{array}{c}\text { Ball velocity } \\
{[\mathrm{mm} / \mathrm{s}]}\end{array}$ & $\begin{array}{c}\text { Disc velocity } \\
{[\mathrm{mm} / \mathrm{s}]}\end{array}$ \\
\hline 0 & 0.0 & 370 & 370 \\
\hline 25 & 92.5 & 416 & 324 \\
\hline 50 & 185.0 & 463 & 278 \\
\hline 75 & 277.5 & 509 & 231 \\
\hline 100 & 370.0 & 555 & 185 \\
\hline 125 & 462.5 & 601 & 139 \\
\hline 150 & 555.0 & 648 & 93 \\
\hline
\end{tabular}

$k_{\mathrm{W}}=\frac{\Delta V}{F \cdot S}$

(eq. 2)

Before the actual evaluation for the results, the running-in involved 22.5 min under the test conditions. The correct running-in procedure was established in many preliminary tests. With this, surface asperities due to machining during the sample preparation were removed. After the running-in phase, the balls were cleaned and dried at $80{ }^{\circ} \mathrm{C}$ for $8 \mathrm{~h}$ to remove any absorbed water and then weighed. Before the start of the test, the balls were left in atmospheric conditions for several days to recondition. After the test was finished, the same drying process was repeated. The duration of the wear test was $225 \mathrm{~min}$, which corresponds to $5000 \mathrm{~m}$ of sliding distance for the tests performed at the SRR of $100 \%$.

It should be noted that the total sliding distance for the different SRRs was not the same, since the number of cycles (gear meshing time), which is the most relevant parameter for the gear design and its durability, was kept the same instead (Table 2). Nevertheless, all the wear results are normalised by sliding distance (and load), to compare the sliding distance as well.

All the tests were performed at least three times and the average values and $( \pm)$ one standard deviation are reported in the diagrams.

The worn surfaces were examined using a scanning electron microscope (SEM, JEOL JSM-IT100, Japan) at an accelerating voltage of $10 \mathrm{kV}$. Prior to the examination, the ball specimens were sputter coated (SCD005, Baltec AG, Liechtenstein) with a 20-nm-thick gold coating (sputtering at a 35-mm working distance using $30 \mathrm{~mA}$ for $100 \mathrm{~s}$ ). 
This peer reviewed manuscript has been accepted for publications to the Wear.

Cite this article as: S. Matkovič, M. Kalin, Effects of slide-to-roll ratio and temperature on the tribological behaviour in polymer-steel contacts and a comparison with the performance of realscale gears, Wear (2021) 477: 203789. DOI: https://doi.org/10.1016/j.wear.2021.203789.

\section{BY-NC-ND}

\subsection{Real-scale gear tests}

In order to validate the results of the SRR effect in the tribological tests and the impact for actual gear applications, the experiments were also performed using our in-house-developed open-loop test rig for real-scale polymer gears (Fig. 2) [23]. The test rig consists of a driving shaft and a driven shaft. The steel pinion is fixed on the driving shaft, which is controlled by a servomotor that adjusts the operating speed. The polymer-gear specimen is mounted on the driven shaft, which is connected to a brake for adjusting the torque with high accuracy $( \pm 1.0 \mathrm{mNm})$. The efficiency of the gear meshing can also be measured with two accurate torque sensors (having a measurement uncertainty of $<0.02 \%$ ). To monitor and control the gear's temperature on the flank and the root in real-time, an IR thermal camera (Optris PI400, Optris GmbH, Germany) together with an insulating chamber around the meshing-gear pair was used. The measurement is connected in a feedback loop, which makes possible a constant gear temperature within $\pm 2{ }^{\circ} \mathrm{C}$ for the specific area of the polymer gear.

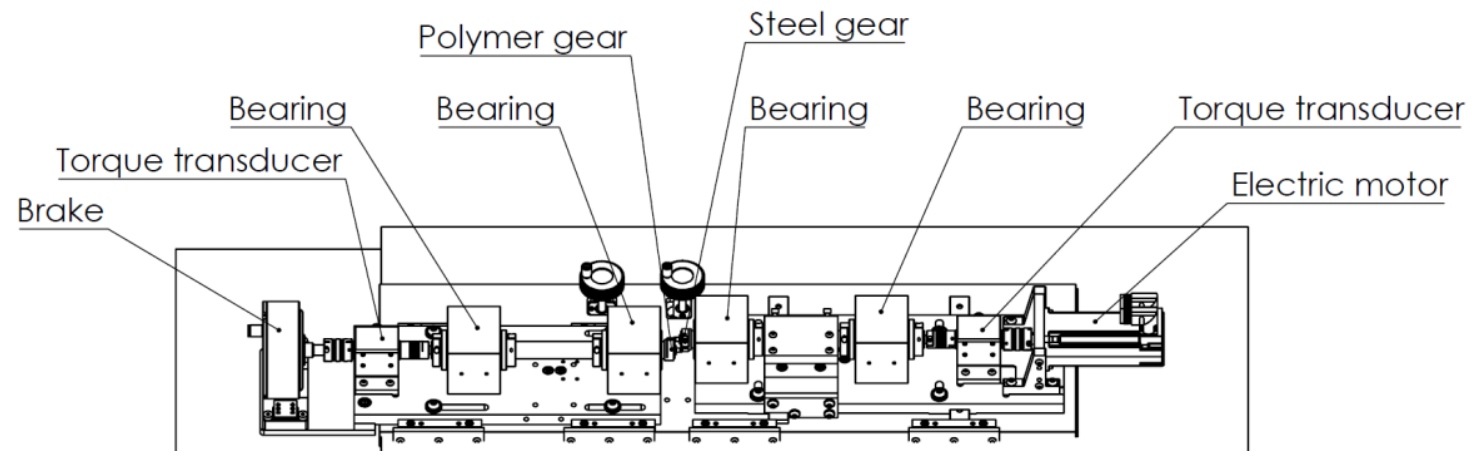

Fig. 2: Schematic of the polymer gear test rig.

To compare the wear mechanisms and the wear coefficient calculated from the ball-on-disc measurements with the wear coefficient from the gear tests, the testing conditions in the gear tests were set to corresponding equivalent contact parameters. The rotational speed of the pinion was set to $1500 \mathrm{rpm}$, which corresponds to $1095 \mathrm{rpm}$ of the polymer gear. Considering the gear geometry from Table 3 , this corresponds to an entrainment velocity of $370 \mathrm{~mm} / \mathrm{s}$, i.e., the same as in the SRR-variable tribological test. The loading torque was set to a value of $0.5 \mathrm{Nm}$ (root stress of $31.26 \mathrm{MPa}$ according to the VDI 2736-2 [27]). The tests were performed at the same constant flank temperatures that were selected for the SRR-variable tribological tests, i.e., $50{ }^{\circ} \mathrm{C}$ and $80{ }^{\circ} \mathrm{C}$. The duration of the tests was 1 million cycles, with a starting running-in phase of $10^{5}$ cycles. The weight loss was measured on an analytical scale by applying a drying process, the same way as for the MTM polymer-ball specimens. The drying process was applied after the running-in phase, and after the test. 
This peer reviewed manuscript has been accepted for publications to the Wear.

Cite this article as: S. Matkovič, M. Kalin, Effects of slide-to-roll ratio and temperature on the tribological behaviour in polymer-steel contacts and a comparison with the performance of realscale gears, Wear (2021) 477: 203789. DOI: https://doi.org/10.1016/j.wear.2021.203789.

CC BY-NC-ND

After the real-scale gear test and the relevant analyses of the full gear (weight), the polymer gears were cut to prepare the worn flanks for an examination under the SEM. Several gear teeth were used from each test to sputter the gold coat and examine the surfaces using the same SEM parameters as described for MTM polymer ball samples.

Table 3: Test-gear specifications.

\begin{tabular}{|l|c|c|}
\hline Parameter & Pinion & Gear \\
\hline Material & $100 \mathrm{Cr} 6$ & Delrin 500P \\
\hline Normal module [mm] & 17 & 22 \\
\hline Number of teeth & 0 & 0 \\
\hline Helix angle [ ${ }^{\circ}$ ] & 8 & 6 \\
\hline Transmission ratio & 20 & 20 \\
\hline Face width [mm] & 0 & 0 \\
\hline $\begin{array}{l}\text { Normal pressure } \\
\text { angle }{ }^{\circ}{ }^{2}\end{array}$ & 6 & 1.29 \\
\hline Profile shift & $1.250 / 0.250 / 0.925$ & $1.250 / 0.300 / 0.825$ \\
\hline Gear quality & \multicolumn{2}{|c|}{} \\
\hline Reference profile & & \\
\hline
\end{tabular}

The coefficient of friction for the gear pair was calculated by measuring the input and output torque. Eq. 3 was used to calculate the total power loss $P_{\mathrm{V}}$. By knowing the load-dependent bearing losses $P_{\mathrm{VLP}}$ (the same parameter and index abbreviations are used as originally defined in VDI 2736-2) of the in-house-designed gear test rig and the load-independent losses $P_{\mathrm{V} 0}$ (measured when the gears were idling), the load-dependent gear meshing power loss $P_{\mathrm{VzP}}$ was calculated (eq. 4). When $P_{\mathrm{VzP}}$ and the input torque $P_{\mathrm{i}}$ are known, eq. 5 can be used to calculate the average coefficient of friction for the gear pair. The degree of tooth loss $H_{\mathrm{V}}$ was calculated according to VDI 2736-2 [27]. Furthermore, the sliding factor along with the Hertzian pressure on the gear flank were calculated using the loaded-tooth contact analyses [28] with KISSsoft software. 
This peer reviewed manuscript has been accepted for publications to the Wear.

Cite this article as: S. Matkovič, M. Kalin, Effects of slide-to-roll ratio and temperature on the tribological behaviour in polymer-steel contacts and a comparison with the performance of realscale gears, Wear (2021) 477: 203789. DOI: https://doi.org/10.1016/j.wear.2021.203789.

CC BY-NC-ND

$P_{\mathrm{V}}=\left(T_{\mathrm{i}}-\frac{1}{i} \cdot T_{\mathrm{o}}\right) \cdot n_{\mathrm{i}} \cdot \frac{2 \cdot \pi}{60}$

$P_{\mathrm{VzP}}=P_{\mathrm{V}}-P_{\mathrm{VLP}}-P_{\mathrm{V} 0}$

$\mu=\frac{P_{\mathrm{VzP}}}{P_{\mathrm{i}} \cdot H_{\mathrm{V}}}$

The wear coefficient of the polymer gear was calculated directly by measuring the weight of the polymer gear and using eq. 6 [27], where $M_{\mathrm{W}}$ is the mass difference, $T_{\mathrm{d}}$ is the nominal torque, $N_{\mathrm{L}}$ is the number of load cycles, $H_{\mathrm{V}}$ is the degree of tooth loss and $\rho$ is the density of the material.

$k_{\mathrm{W}}=\frac{M_{\mathrm{W}}}{T_{\mathrm{d}} \cdot 2 \cdot \pi \cdot N_{\mathrm{L}} \cdot H_{\mathrm{V}} \cdot \rho}$

Due to variations in the contact conditions, i.e., geometry, velocity and pressure, along the gear flanks, these parameters need to be extracted from calculations for specific gears to allow a comparison with well-defined model tribological tests, like those used in this study.

The plot in Fig. 3a shows Hertzian pressures, while Fig. $3 b$ presents the sliding velocities on the gear flanks. Both of the plots were calculated using KISSsoft software [26]. Due to the lower modulus of elasticity at a higher temperature, both the pressure on the gear flank and the sliding velocities were lower at $80{ }^{\circ} \mathrm{C}$ than at $50{ }^{\circ} \mathrm{C}$. Furthermore, the contact path (represented as the angle of rotation of a steel pinon) was longer at the higher temperature of $80^{\circ} \mathrm{C}$, which is seen in Figs. $3 \mathrm{a}$ and $3 \mathrm{~b}$ from the larger angle of rotation.

From the calculated sliding-velocity profile along the contact path, the actual SRR values on the gear flanks can be calculated by dividing the velocity at a given point by the entrainment speed $(0.37 \mathrm{~m} / \mathrm{s})$. The SRR values together with the theoretical contact points (A-E) along the gear flank contact path are also presented in Fig. 3. 
This peer reviewed manuscript has been accepted for publications to the Wear.

Cite this article as: S. Matkovič, M. Kalin, Effects of slide-to-roll ratio and temperature on the tribological behaviour in polymer-steel contacts and a comparison with the performance of realscale gears, Wear (2021) 477: 203789. DOI: https://doi.org/10.1016/j.wear.2021.203789.

\section{BY-NC-ND}
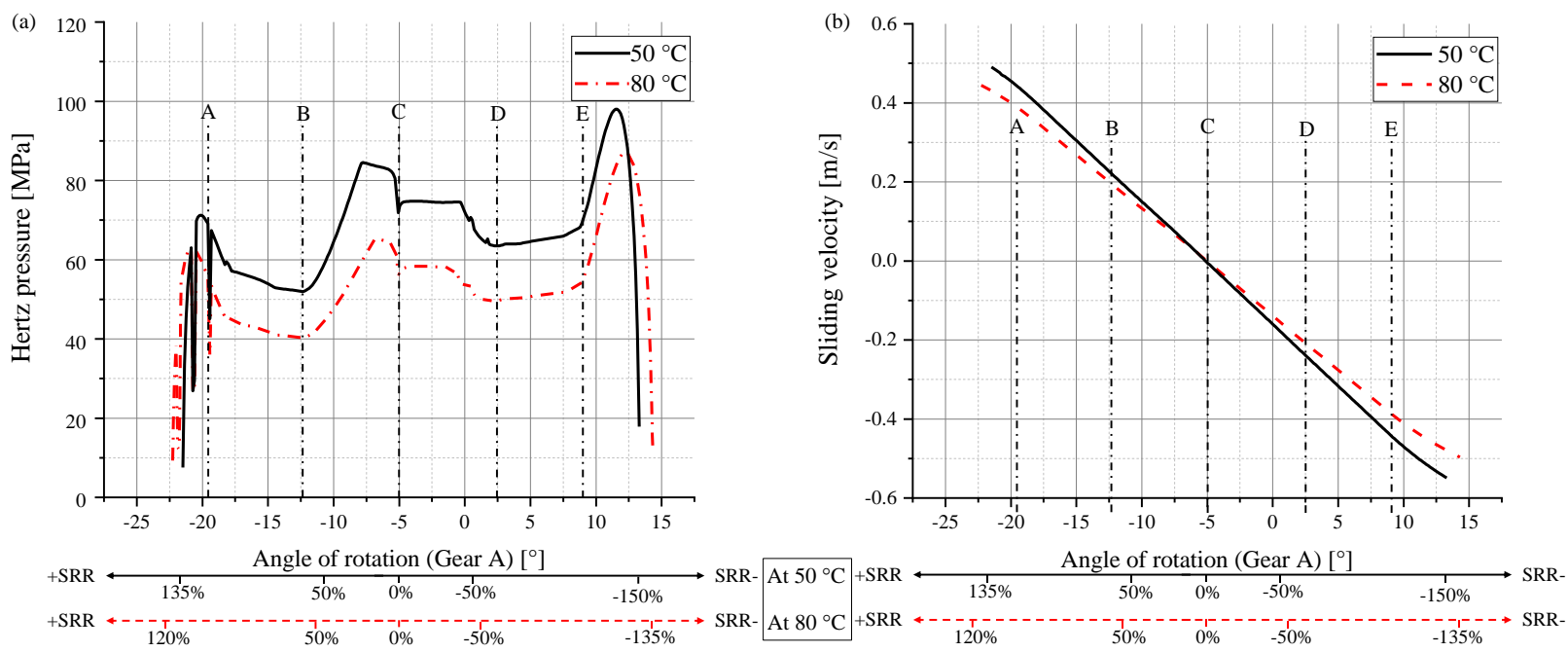

Fig. 3: (a) Hertzian pressure and (b) sliding velocity on the gear flank.

\section{Results}

\subsection{Friction and wear from the tribological model tests}

Fig. 4 presents the coefficients of friction in terms of the SRR for two different loads and at (a) $50{ }^{\circ} \mathrm{C}$ and (b) $80{ }^{\circ} \mathrm{C}$. In the pure-rolling condition (SRR = 0), the coefficient of friction was 0.06 at $8 \mathrm{~N}$ and 0.09 at $45 \mathrm{~N}$, tested at $50{ }^{\circ} \mathrm{C}$. At $80{ }^{\circ} \mathrm{C}$ the coefficient of friction was slightly higher. At $8 \mathrm{~N}$ it was 0.10 and at $45 \mathrm{~N}$ it was 0.11 .

When the SRR increased to $25 \%$, the coefficient of friction changed considerably. At $50{ }^{\circ} \mathrm{C}$ the coefficient of friction increased to $\sim 0.25$ and was almost the same for both loads. In the case of $80{ }^{\circ} \mathrm{C}$, the coefficient of friction was lower at $8 \mathrm{~N}$, i.e., 0.2 , whereas at the higher load of $45 \mathrm{~N}$ the friction was 0.25 , which was similar to the case of $50{ }^{\circ} \mathrm{C}$.

When the SRR increased further to a value of $50 \%$, the friction coefficient also increased for all four test combinations. For the tests conducted at $50{ }^{\circ} \mathrm{C}$ the friction coefficient increased to $\sim 0.3$ for both loads, whereas for the higher temperature it increased to a lower value, i.e., to 0.26 at $8 \mathrm{~N}$ and to 0.29 at the higher load.

For $75 \%$ SRR the friction coefficient at the lower temperature $\left(50{ }^{\circ} \mathrm{C}\right)$ increased to 0.31 for both loads, while at $80{ }^{\circ} \mathrm{C}$ the friction at $8 \mathrm{~N}$ increased to 0.3 . However, at $80{ }^{\circ} \mathrm{C}$ the coefficient of friction did not increase at $45 \mathrm{~N}$, but remained constant. 
This peer reviewed manuscript has been accepted for publications to the Wear.

Cite this article as: S. Matkovič, M. Kalin, Effects of slide-to-roll ratio and temperature on the tribological behaviour in polymer-steel contacts and a comparison with the performance of realscale gears, Wear (2021) 477: 203789. DOI: https://doi.org/10.1016/j.wear.2021.203789.

CC BY-NC-ND

When the SRR increased even further, from $75 \%$ to $150 \%$, the coefficient of friction also increased to 0.33 for $8 \mathrm{~N}$ at both temperatures. Nevertheless, for the higher load of $45 \mathrm{~N}$, this was not the case. The coefficient of friction remained constant, or it even decreased at the highest SRRs (125\% and $150 \%$ ). Therefore, for the highest SRR tested it was $\sim 0.26$ for the test conducted at $50{ }^{\circ} \mathrm{C}$ and $\sim 0.27$ for $80{ }^{\circ} \mathrm{C}$.

Overall, the trend was similar for both temperatures, i.e., with an increasing slide-to-roll ratio at the low load $(8 \mathrm{~N})$, the coefficient of friction was increasing. However, at the high load (45 N) the coefficient of friction reached a plateau (at the high temperature only) and at the highest SRR values, it even decreased after $75 \% \mathrm{SRR}$ at $50{ }^{\circ} \mathrm{C}$ and after $125 \% \mathrm{SRR}$ at $80{ }^{\circ} \mathrm{C}$. On average, the standard deviation of all the results was within $6 \%$.

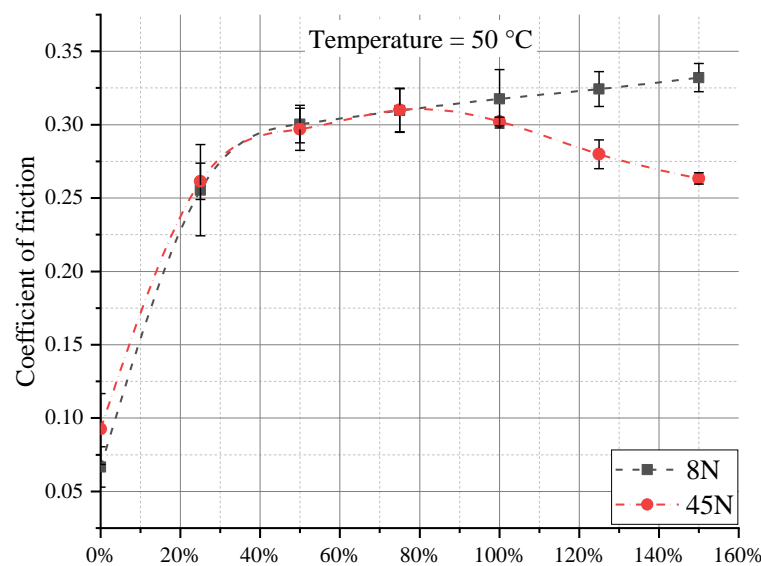

(a)

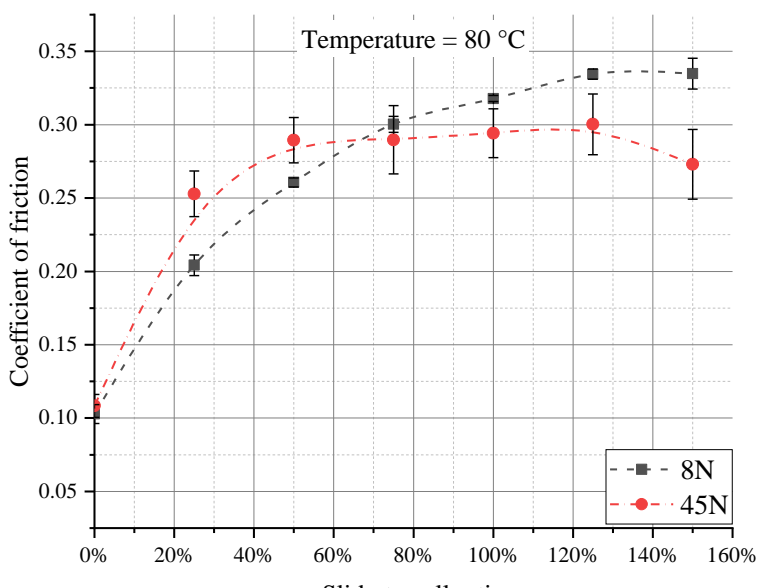

Slide-to-roll ratio

Fig. 4. Coefficient of friction as a function of SRR at (a) $50{ }^{\circ} \mathrm{C}$ and (b) $80{ }^{\circ} \mathrm{C}$.

Fig. 5a presents the wear loss of the polymer balls at the two different loads for $50 \%$ SRR at both temperatures. The wear loss was in the range $1.18 \times 10^{-3} \mathrm{~g}$ to $4.26 \times 10^{-3} \mathrm{~g}$. The comparison showed that the wear loss was greater at the higher load. This difference was $31-33 \%$ for both temperatures. Furthermore, with the higher temperature the wear loss was slightly higher for both loads. The difference was $10 \%$ for $8 \mathrm{~N}$ and $17 \%$ for $45 \mathrm{~N}$.

In Fig. 5b, the wear coefficient for the polymer ball is presented. It is interesting to note that the wear coefficient was higher at the low load $(8 \mathrm{~N})$ than at the high load $(45 \mathrm{~N})$, which was true for the high and low temperatures. Moreover, the wear coefficient was slightly higher at the high temperature. 
This peer reviewed manuscript has been accepted for publications to the Wear.

Cite this article as: S. Matkovič, M. Kalin, Effects of slide-to-roll ratio and temperature on the tribological behaviour in polymer-steel contacts and a comparison with the performance of realscale gears, Wear (2021) 477: 203789. DOI: https://doi.org/10.1016/j.wear.2021.203789.

\section{BY-NC-ND}

(a)

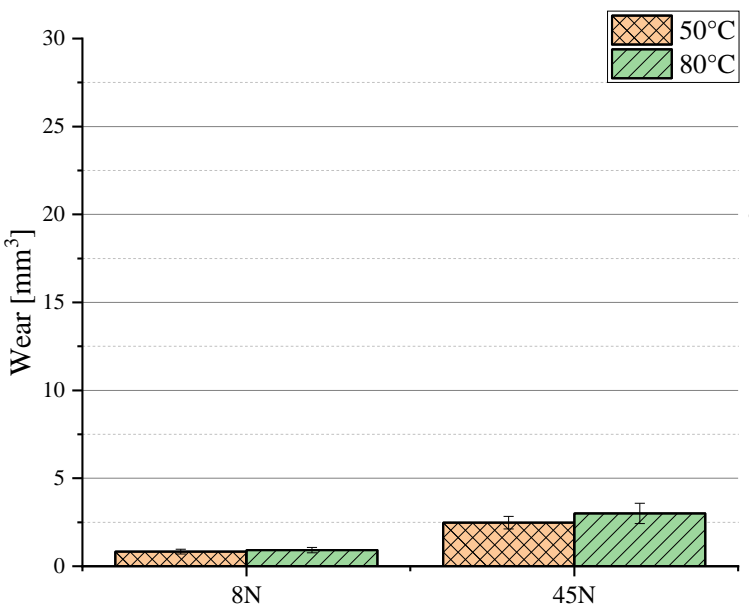

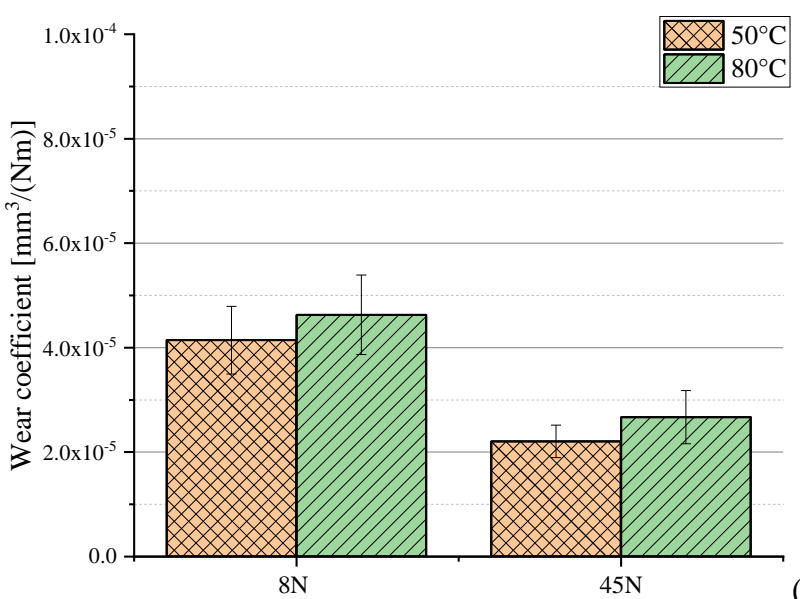

(b)

Fig. 5. Influence of load at constant 50\% SRR on (a) wear and (b) wear coefficient of the polymer ball at $50{ }^{\circ} \mathrm{C}$ and $80^{\circ} \mathrm{C}$.

When the SRR increased, the wear loss also increased (Fig. 6a). The wear increase was higher for the tests performed at the low temperature of $50{ }^{\circ} \mathrm{C}$ : when the SRR changed from $50 \%$ to $100 \%$, the wear increased by 4.3 times. When the SRR changed from $100 \%$ to $150 \%$, the wear further increased by 2.26 times, and thus the total increase from $50 \%$ to $150 \%$ SRR was 9.78 times. In the case of the higher temperature of $80{ }^{\circ} \mathrm{C}$, the wear increase was 1.15 times for the SRR change from $50 \%$ to $100 \%$ and 3.62 times for the $100 \%$ to $150 \%$, in total from $50 \%$ to $150 \%$ it was 4.18 times.

A comparison between the different temperatures shows that at the higher SRR values (100 and $150 \%$ ), the wear was smaller for the higher-temperature tests. As an example, for SRR $100 \%$ the wear at $50{ }^{\circ} \mathrm{C}$ was 3.1-times larger compared to the test conducted under $80{ }^{\circ} \mathrm{C}$ and for SRR $150 \%$, the wear was 1.93 -times larger at the lower temperature of $50{ }^{\circ} \mathrm{C}$. 
This peer reviewed manuscript has been accepted for publications to the Wear.

Cite this article as: S. Matkovič, M. Kalin, Effects of slide-to-roll ratio and temperature on the tribological behaviour in polymer-steel contacts and a comparison with the performance of realscale gears, Wear (2021) 477: 203789. DOI: https://doi.org/10.1016/j.wear.2021.203789.

\section{BY-NC-ND}

(a)
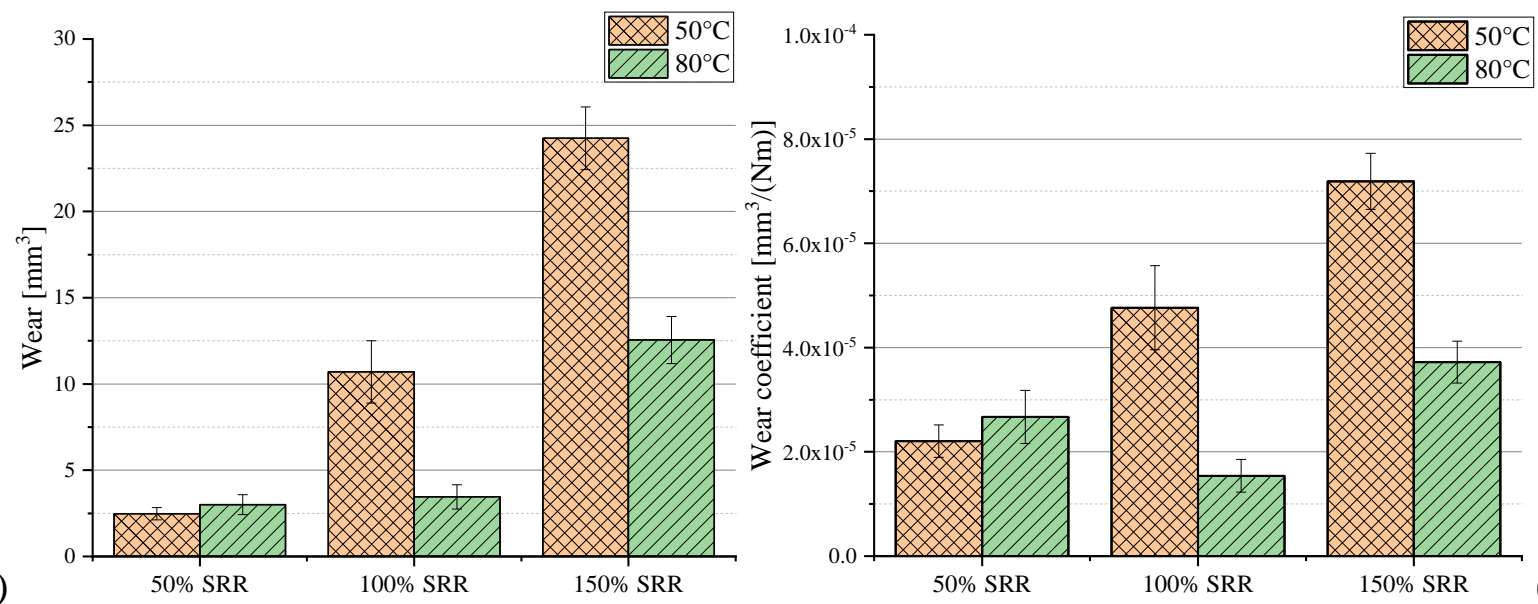

(b)

Fig. 6. Influence of SRR at a constant $45 \mathrm{~N}$ load on (a) wear and (b) wear coefficient of the polymer ball at $50{ }^{\circ} \mathrm{C}$ and $80{ }^{\circ} \mathrm{C}$.

\subsection{SEM analyses of the surfaces from the tribological model tests}

SEM images of the POM ball tested with 50\% SRR at 8 and $45 \mathrm{~N}$, as well as 50 and $80{ }^{\circ} \mathrm{C}$, are presented in Fig. 7. There is very small wear damage observed at $8 \mathrm{~N}$ for both temperatures, and this small difference is thus also characteristic for the surfaces tested at the low (Fig. 7a) and high (Fig. 7b) temperatures. Some small ridges and individual wear debris are present on both surfaces. As the load increased to $45 \mathrm{~N}$, the wear behaviour did not show obvious wear-mechanism changes, although an increased number of cracks was observed, see Fig. 8. These cracks, perpendicular to the sliding direction, are noted mainly at $50{ }^{\circ} \mathrm{C}$, rather than at $80^{\circ} \mathrm{C}$. This might indicate more mechanical-based loading and wear at $50{ }^{\circ} \mathrm{C}$ than at $80^{\circ} \mathrm{C}$. However, obvious signs of temperature-related wear mechanisms were not observed at any load or temperature with $50 \%$ SRR. 
This peer reviewed manuscript has been accepted for publications to the Wear.

Cite this article as: S. Matkovič, M. Kalin, Effects of slide-to-roll ratio and temperature on the tribological behaviour in polymer-steel contacts and a comparison with the performance of realscale gears, Wear (2021) 477: 203789. DOI: https://doi.org/10.1016/j.wear.2021.203789.

(a)
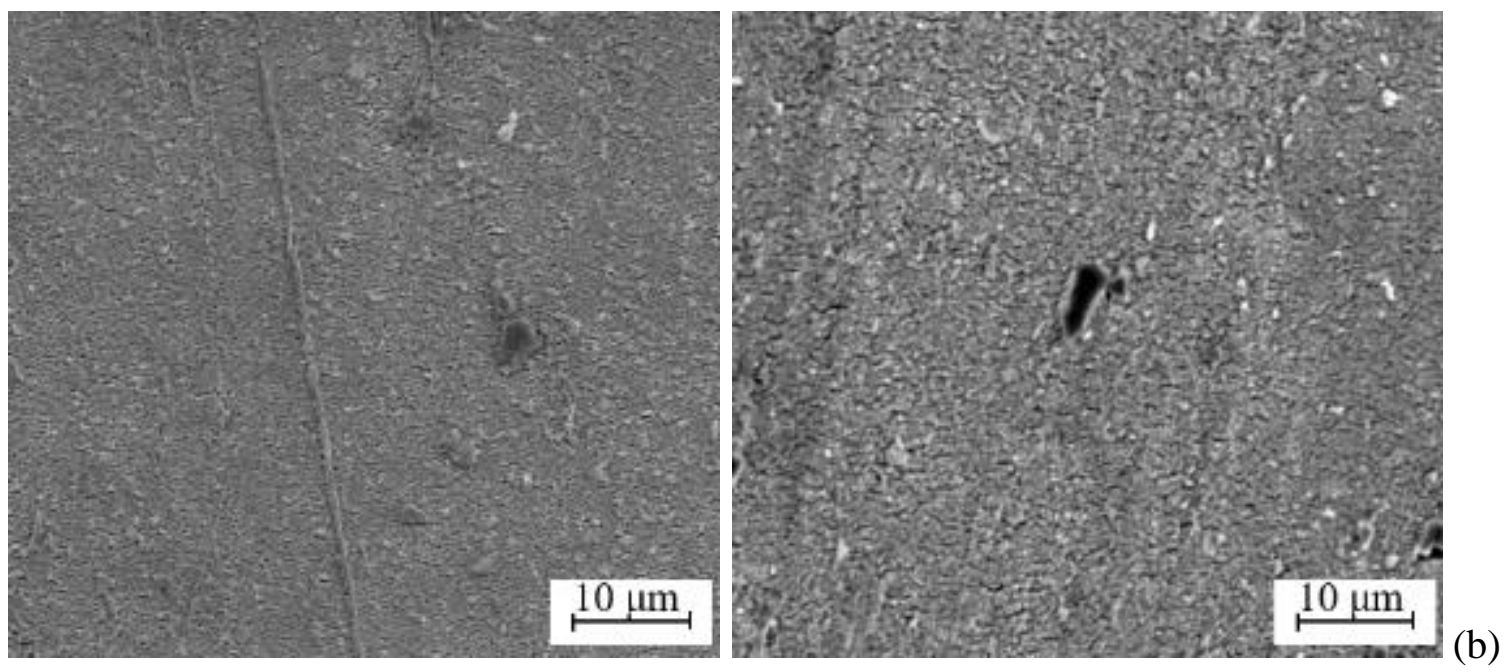

Fig. 7: SEM image of polymer-ball contact area tested with $50 \%$ SRR at $8 \mathrm{~N}$ at (a) $50{ }^{\circ} \mathrm{C}$, (b) $80{ }^{\circ} \mathrm{C}$.

(a)
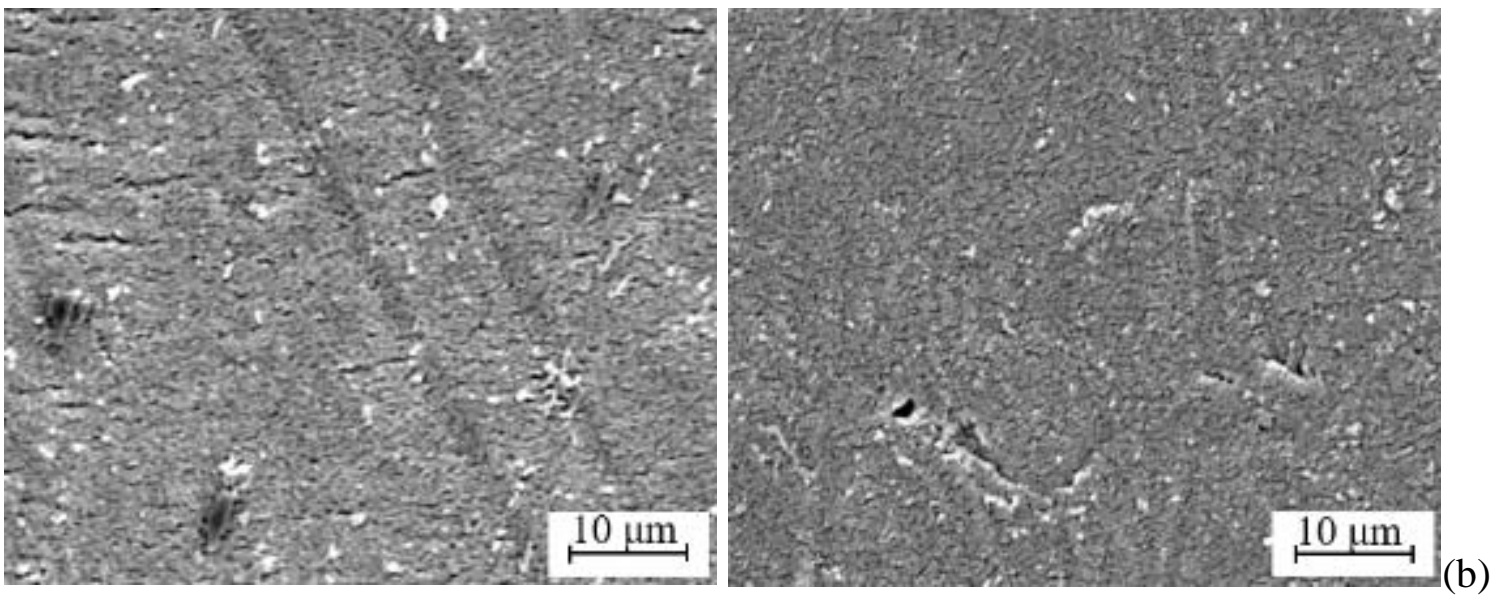

Fig. 8: SEM image of polymer-ball contact area tested with $50 \% \mathrm{SRR}$ at $45 \mathrm{~N}$ at (a) $50{ }^{\circ} \mathrm{C}$, (b) $80{ }^{\circ} \mathrm{C}$.

As the SRR ratio changed from 50\% to $100 \%$ (Fig. 9) and 150\% SRR (not shown), the topography of the worn surface changed and became very temperature dependent. At $50{ }^{\circ} \mathrm{C}$ the wear is still mechanically based, but contains much more sliding evidence than the $50 \% \mathrm{SRR}$, as seen from the many perpendicular ridges (Fig. 9a). However, significant thermal deformation is not observed. Although a smooth layer is seen at high magnification (Fig. 9b), which can indicate some thermally driven behaviour, the cracks and strongly oriented ridges indicate the strength of the material was largely maintained. In contrast, at $80{ }^{\circ} \mathrm{C}$, the ball surface was completely changed, becoming fully covered by adhered material (Fig. 9c), with no mechanical-based wear mechanism noted, apart 
This peer reviewed manuscript has been accepted for publications to the Wear.

Cite this article as: S. Matkovič, M. Kalin, Effects of slide-to-roll ratio and temperature on the tribological behaviour in polymer-steel contacts and a comparison with the performance of realscale gears, Wear (2021) 477: 203789. DOI: https://doi.org/10.1016/j.wear.2021.203789.

from tearing off the large flakes of adhered layers (Fig. 9d). Therefore, the wear mechanism was strongly thermal at the high SRR values (100 and 150\%) and $80{ }^{\circ} \mathrm{C}$.

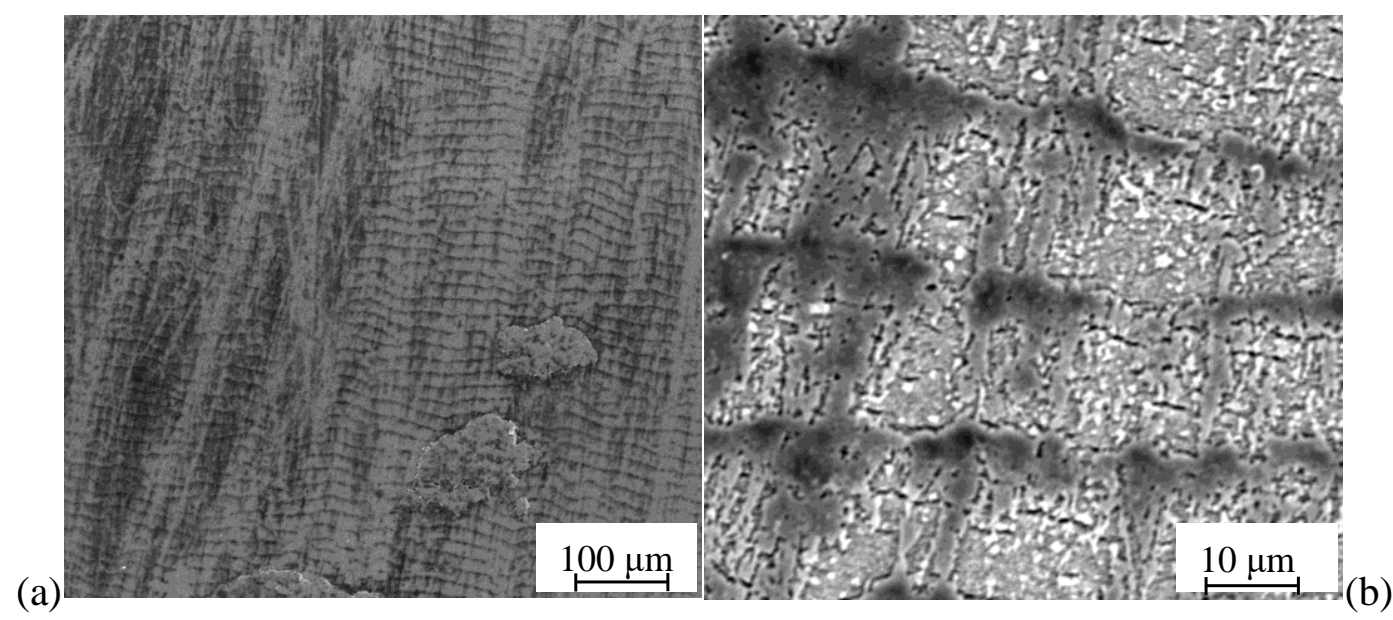

(c)
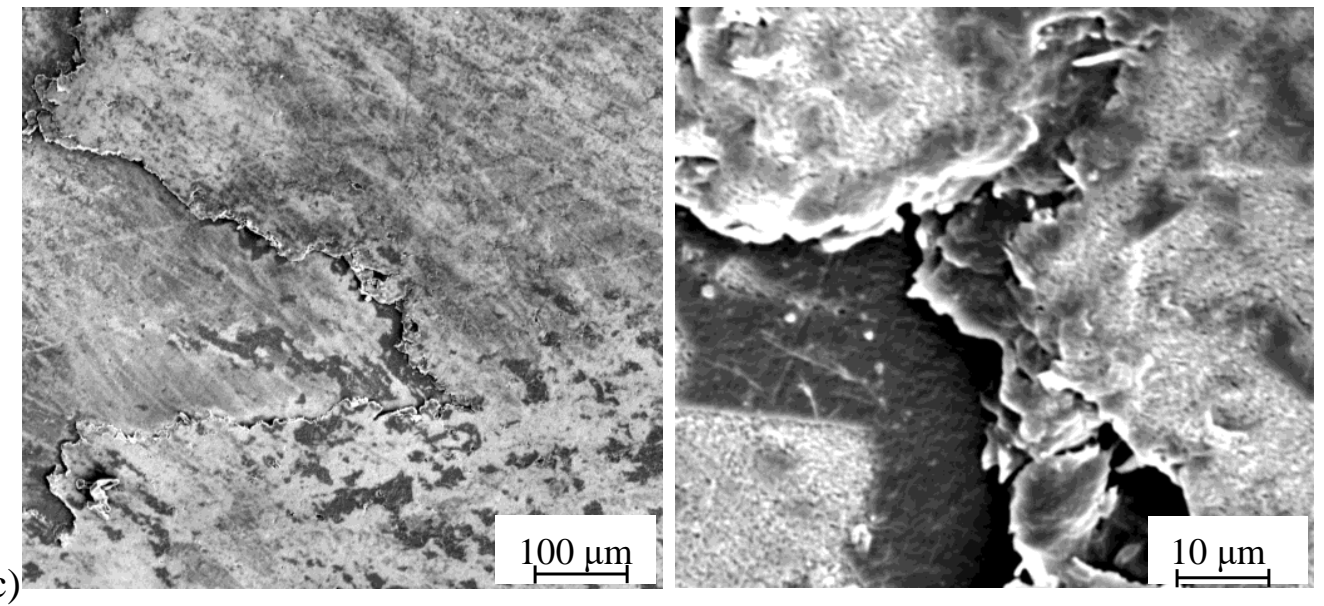

(d)

Fig. 9: SEM images of polymer-ball specimen tested at $100 \%$ SRR at $45 \mathrm{~N}$ at $50{ }^{\circ} \mathrm{C}$ : (a) an overview and (b) detail; and at $80^{\circ} \mathrm{C}$ : (c) an overview and (d) detail.

The steel disc specimens showed no wear at any condition used in this work. The only feature, which was, however, observed on all steel surfaces was a thin polymer transfer film that covered the asperities in the wear tracks. In spite of difference in hardness between polymer and steel 
This peer reviewed manuscript has been accepted for publications to the Wear.

Cite this article as: S. Matkovič, M. Kalin, Effects of slide-to-roll ratio and temperature on the tribological behaviour in polymer-steel contacts and a comparison with the performance of realscale gears, Wear (2021) 477: 203789. DOI: https://doi.org/10.1016/j.wear.2021.203789.

CC BY-NC-ND

samples and clearly visible scratches on the steel discs (at high magnification) that remained from sample preparation to a specific roughness value, there was no significant abrasive action from these scratches. Namely, the asperity valleys contain no polymer. Accordingly, the transfer film was not substantial and was very thin, however, it is obvious that the ultimate real contact area consisted broadly from polymer-polymer interactions at the surface asperities.

SEM images of the steel discs tested with $50 \%$ SRR at $45 \mathrm{~N}$ at both 50 and $80{ }^{\circ} \mathrm{C}$, are presented in Fig. 10. There is a small amount of transfer film on both temperatures, however at $80{ }^{\circ} \mathrm{C}$ the film is more widely spread over the disc surface and appear thinner. Increasing the SRR ratio at $45 \mathrm{~N}$ from $50 \%$ (Fig. 10) to $100 \%$ (Fig. 11) and 150\% SRR (not shown), the transfer film become even more uniformly spread over the entire disc contact surface, showing more plastic nature, but also appear thinner. Similar observations are valid also for load of $8 \mathrm{~N}$, with even less transfer film present.

(a)
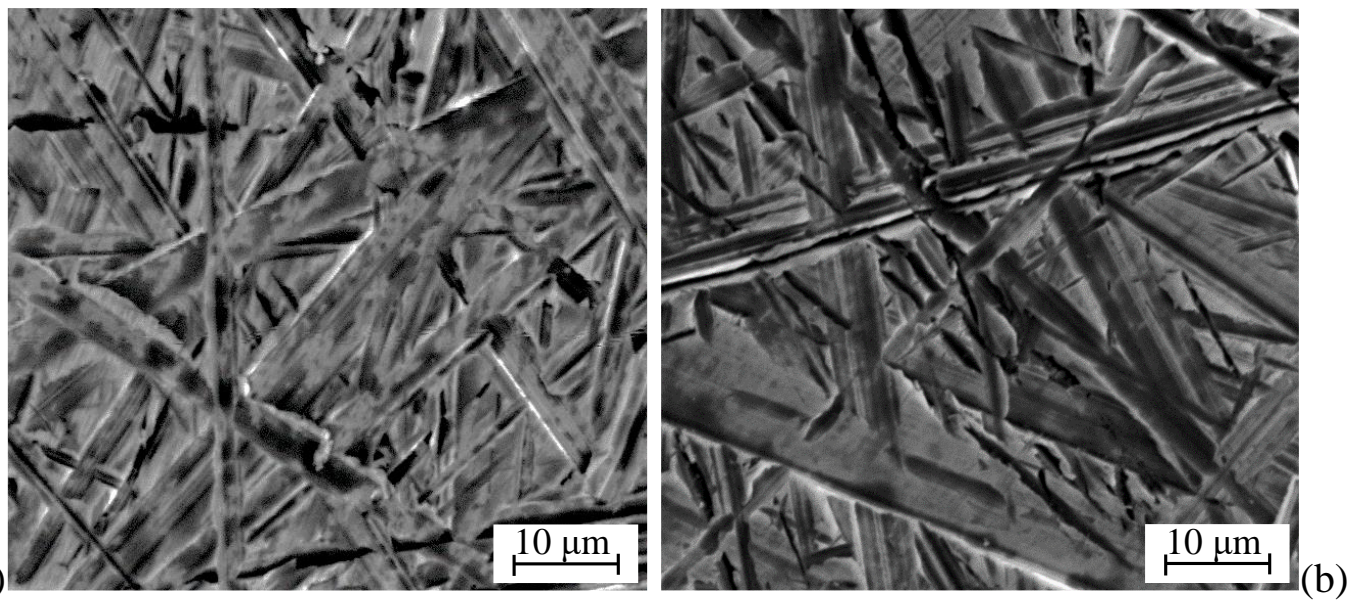

Fig. 10: SEM images of steel-disc specimens tested at 50\% SRR at $45 \mathrm{~N}$ at (a) $50{ }^{\circ} \mathrm{C}$, (b) $80{ }^{\circ} \mathrm{C}$. 
This peer reviewed manuscript has been accepted for publications to the Wear.

Cite this article as: S. Matkovič, M. Kalin, Effects of slide-to-roll ratio and temperature on the tribological behaviour in polymer-steel contacts and a comparison with the performance of realscale gears, Wear (2021) 477: 203789. DOI: https://doi.org/10.1016/j.wear.2021.203789.

\section{BY-NC-ND}

(a)
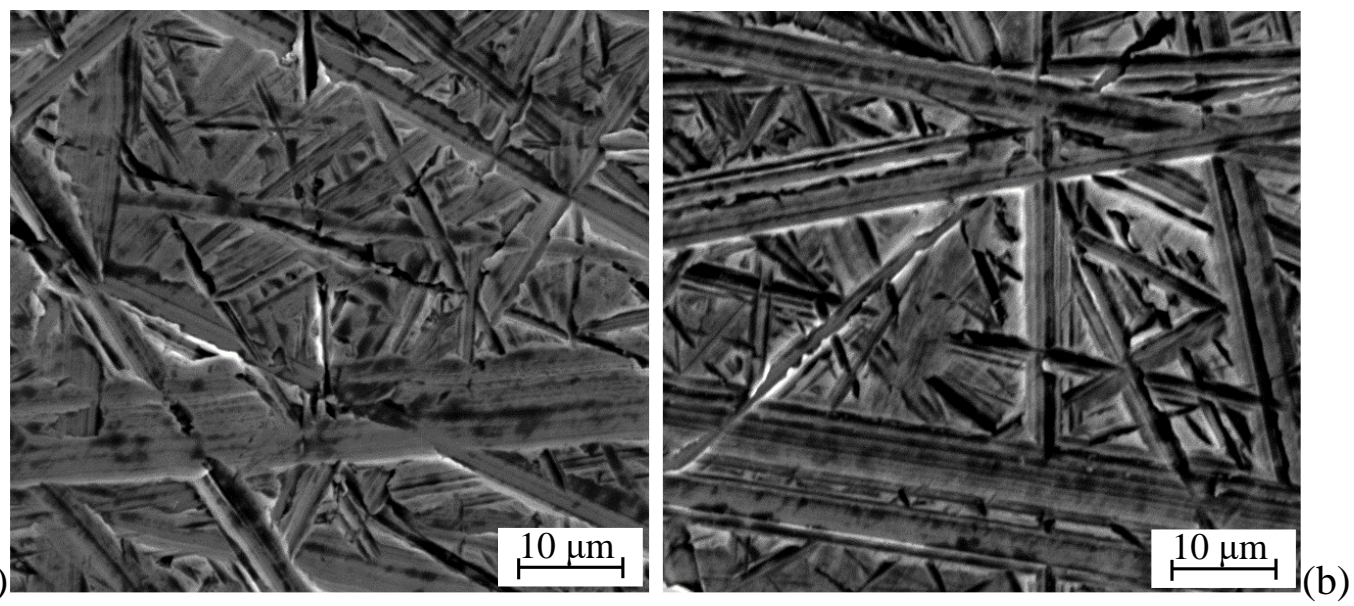

Fig. 11: SEM images of steel-disc specimens tested at $100 \% \mathrm{SRR}$ at $45 \mathrm{~N}$ at (a) $50{ }^{\circ} \mathrm{C}$, (b) $80{ }^{\circ} \mathrm{C}$.

\subsection{Results obtained from gear tests}

The average coefficient of friction for the steel/polymer gear-pair meshing at $50{ }^{\circ} \mathrm{C}$ was 0.29 , and at $80^{\circ} \mathrm{C}$ the average coefficient of friction was slightly lower, i.e., 0.28 . The wear coefficient of the gears meshing at $50{ }^{\circ} \mathrm{C}$ was $5.1 \cdot 10^{-6} \mathrm{~mm}^{3} /(\mathrm{Nm})$, while for the gears that run at $80{ }^{\circ} \mathrm{C}$ the wear coefficient was $2.1 \cdot 10^{-6} \mathrm{~mm}^{3} /(\mathrm{Nm})$. Therefore, the gears meshing at the higher temperature exhibit a lower wear coefficient by around $40 \%$. Although surprising at first sight, the higher wear coefficient at $50{ }^{\circ} \mathrm{C}$ was also noted in the SRR-variable tribological tests at high SRR values (see Fig. 6). Detailed empirical tribological data from the real-scale gear tests are given in Table 4.

Table 4: Results obtained from a gear after 1 million cycles of meshing at a torque of $0.5 \mathrm{Nm}$.

\begin{tabular}{|c|c|c|}
\hline \multirow{2}{*}{} & \multicolumn{2}{|c|}{ Test performed at: } \\
\cline { 2 - 3 } & $\mathbf{5 0}{ }^{\circ} \mathbf{C}$ & $\mathbf{8 0}^{\circ} \mathbf{C}$ \\
\hline Coefficient of friction & $0.29 \pm 0.03$ & $0.28 \pm 0.04$ \\
\hline Wear $\left[\mathrm{mm}^{3}\right]$ & $2.87 \pm 0.40$ & $1.13 \pm 0.19$ \\
\hline Wear coefficient $\left[\mathbf{m m}^{3} /(\mathbf{N m})\right]$ & $5.10 \cdot 10^{-6} \pm 7.13 \cdot 10^{-7}$ & $2.01 \cdot 10^{-6} \pm 3.43 \cdot 10^{-7}$ \\
\hline
\end{tabular}

The gear-flank overview SEM image of the gear meshed at $50{ }^{\circ} \mathrm{C}$ for one million cycles is presented in Fig. 12. The characteristic gear kinematic points (A-E) are marked on the image at the theoretical positions. At $50{ }^{\circ} \mathrm{C}$ they almost ideally coincide with the real meshing conditions, as seen from the surface conditions, described in detail below. In the area of the double-tooth contact, between points $\mathrm{A}-\mathrm{B}$ and $\mathrm{D}-\mathrm{E}$, the wear damage is minimal. In the area below point $\mathrm{E}$, where the tooth was not in contact, there are only some ejected wear debris from the contact, with 
This peer reviewed manuscript has been accepted for publications to the Wear.

Cite this article as: S. Matkovič, M. Kalin, Effects of slide-to-roll ratio and temperature on the tribological behaviour in polymer-steel contacts and a comparison with the performance of realscale gears, Wear (2021) 477: 203789. DOI: https://doi.org/10.1016/j.wear.2021.203789.

CC BY-NC-ND

no wear. The region of the single contact area, i.e., B-C and C-D, has some characteristic ridges, typical of severe sliding with plastic deformation (see Figs. 12b and 12d). These ridges are like those observed in Figs. 8, 9 from our model tribological tests. Moreover, similar ridges were also described in [21], noted as "smearing". These features are much clearer and more obvious in the area above the pitch line, from B-C (Fig. 12b), where the relative velocity is positive (addendum). Their orientation was perpendicular to the direction of sliding, and are smeared towards the pitch line in the direction of the sliding direct ion. The features are approximately $25-150 \mu \mathrm{m}$ long and $3-5 \mu \mathrm{m}$ thick. The gap between the features is almost equal between all of them in the range of 10 to $15 \mu \mathrm{m}$.

Below the pitch line (C-D), in the negative sliding velocity region (dedendum), there are only some features visible, see Fig. 12d. The ridges are also oriented perpendicular to the direction of sliding, but smeared towards the pitch line - as the relative velocity. However, in this region fewer features are present in comparison to the area above the pitch line, so no consistent measurement of their position was obtained.

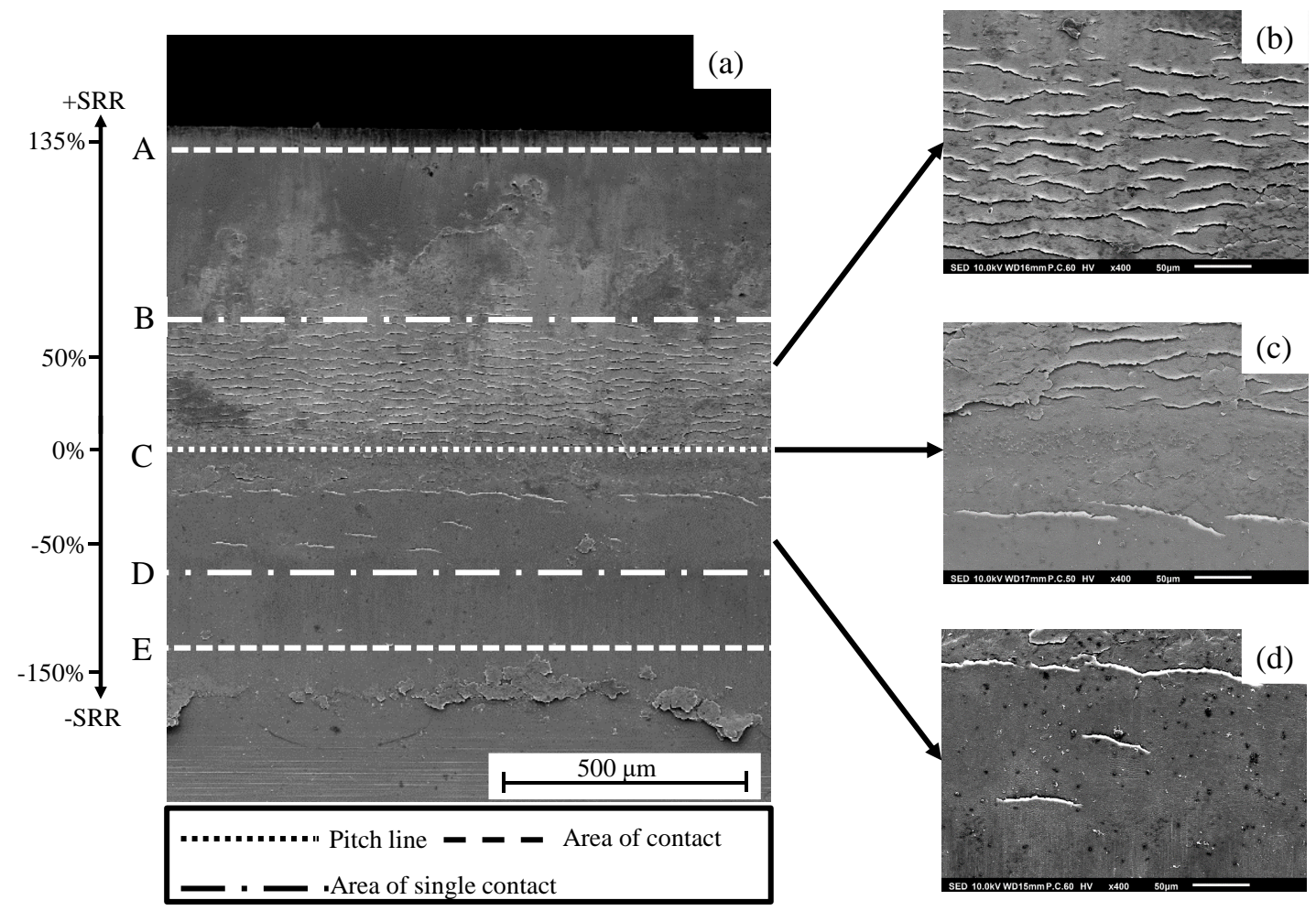

Fig. 12: SEM image of POM gear that meshed at $50{ }^{\circ} \mathrm{C}$ after 1 million cycles: (a) overview and magnification of (b) addendum, (c) pitch line, (d) dedendum region. 
This peer reviewed manuscript has been accepted for publications to the Wear.

Cite this article as: S. Matkovič, M. Kalin, Effects of slide-to-roll ratio and temperature on the tribological behaviour in polymer-steel contacts and a comparison with the performance of realscale gears, Wear (2021) 477: 203789. DOI: https://doi.org/10.1016/j.wear.2021.203789.

\section{BY-NC-ND}

The pitch line (position C), where in theory only the rolling motion is present and the coefficient of friction is the lowest, is shown in Fig. 12c. The pitch line with the width of approximately $75 \mu \mathrm{m}$ lies in between the smearing features from the addendum and dedendum regions. As expected, no smearing features are seen. However, there are some small holes, with diameters between 2 and $5 \mu \mathrm{m}$ as well as some adhered material flakes, which are pushed from the addendum or dedendum regions, adhering due to the highest pressure being in this region.

Fig. 13 presents an overview of the tooth from the gear meshing at $80{ }^{\circ} \mathrm{C}$ with the theoretical tooth characteristic points marked. In this case, the points do not coincide as much as for the gear meshing at $50{ }^{\circ} \mathrm{C}$. Therefore, the marked theoretical pitch line was moved to coincide with the gear-tooth pitch line; however, the distance between the points was kept constant. Moreover, it can be seen in the areas both above A and below E that the tooth was also in contact. Additionally, there are no adhered wear debris in the area near the root of the tooth, which was not the case at $50{ }^{\circ} \mathrm{C}$.

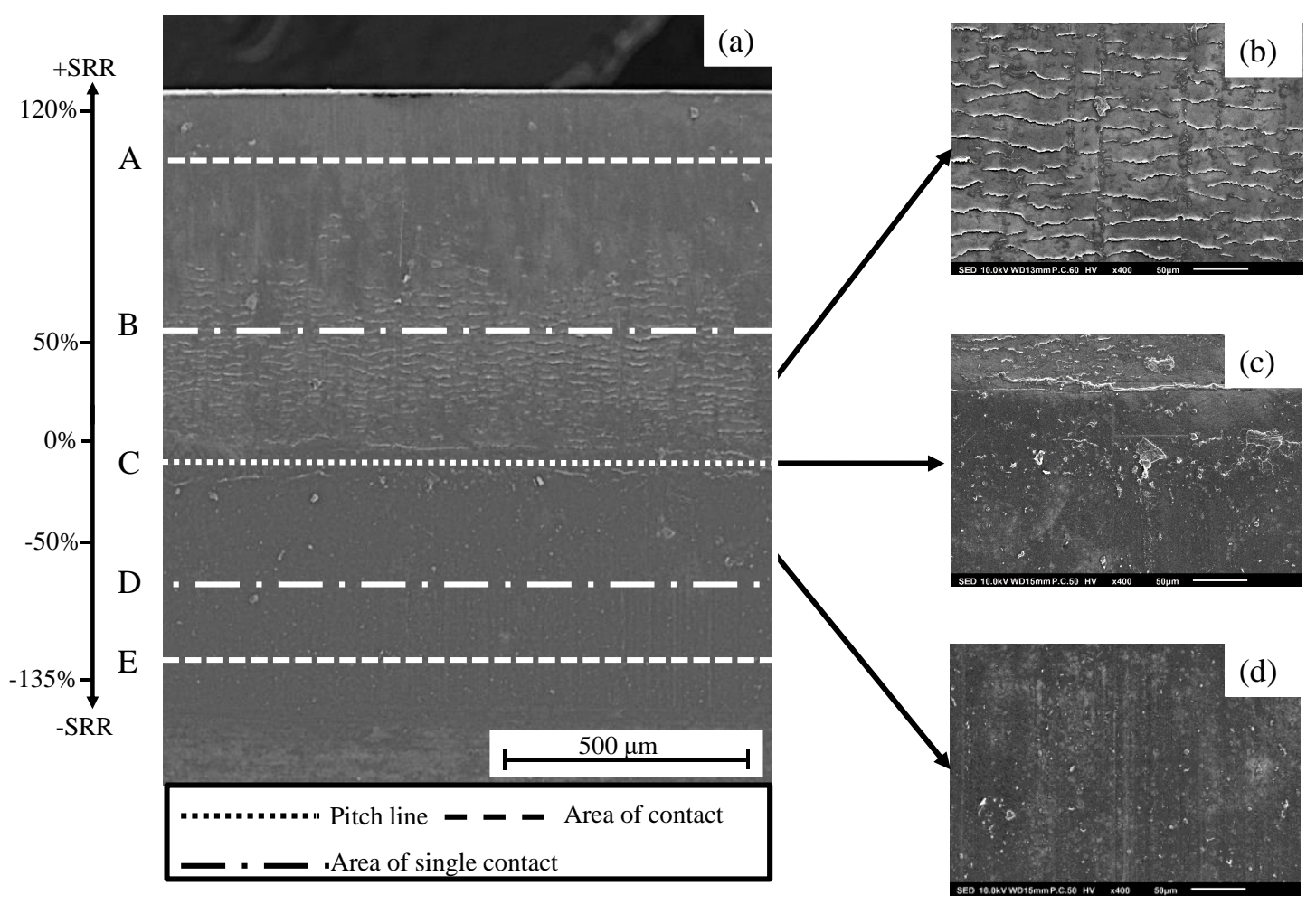

Fig. 13: SEM image of POM gear that meshed at $80^{\circ} \mathrm{C}$ after 1 million cycles: (a) overview and magnification of (b) addendum, (c) pitch line, (d) dedendum region.

Similar to the gear meshing at $50{ }^{\circ} \mathrm{C}$, the more worn-out region is above the pitch line (Fig. 13b), where many of the smearing features are present. These features are also present above the B point, 
This peer reviewed manuscript has been accepted for publications to the Wear.

Cite this article as: S. Matkovič, M. Kalin, Effects of slide-to-roll ratio and temperature on the tribological behaviour in polymer-steel contacts and a comparison with the performance of realscale gears, Wear (2021) 477: 203789. DOI: https://doi.org/10.1016/j.wear.2021.203789.

CC BY-NC-ND

which is another indication that the theoretical lines do not coincide so well as for the tooth meshing at $50{ }^{\circ} \mathrm{C}$. The smearing features are mostly $50 \mu \mathrm{m}$ long, with some exceptions that are $140 \mu \mathrm{m}$. Also, in the case of gear meshing at $80^{\circ} \mathrm{C}$, the gap between the different smearing features is in the range 10 to $15 \mu \mathrm{m}$. However, the features are a bit thinner, at $1-3 \mu \mathrm{m}$, than the ones on a gear that meshed at $50{ }^{\circ} \mathrm{C}$.

Below the pitch line (Fig. 13d) there are only some smearing features, which are near the pitch line. However, some features are not perpendicular to the sliding direction (as smearing lines), but aligned with the sliding direction. It appears that those features are abrasive lines caused by the steel pinon, due to the lower contact pressures and the high SRRs present in that region (see Fig. 3).

On the pitch line (Fig. 13c), some wear debris are present together with small holes, which is similar to the pitch line of the gear running at $50{ }^{\circ} \mathrm{C}$. However, those holes are present in smaller numbers.

Figs. 14 and 15 show SEM images of the steel counter-gears at both tested temperatures, namely 50 and $80{ }^{\circ} \mathrm{C}$. Similarly to model tribological tests there was no wear of steel gears. However, there was a thin polymer transfer film noticed on all sliding regions of the steel gear flanks, having a non-zero SRR, suggesting a polymer-polymer sliding interactions. The same general transfer film characteristics on steel gears can be noticed for both temperatures, see Figs. 14 and 15. The amount of transfer film vary along the meshing positions from almost none around pitch line (point $\mathrm{C})$, which is characteristic for no or small sliding $(\mathrm{SRR}=0)$, to a clear and well-defined film away from pitch line, but it remained thin under all contact conditions. Along the characteristic meshing points A, B and D no distinctive differences in film properties was observed, which is true for both temperatures. Namely, the film was very thin and quite uniform. This is due to a simultaneous increase of the SRR and a decrease of the contact pressure. The most pronounced transfer film was always noticed at the tip of the steel gear in the point E, which is due to high values of both, pressure and SRR (Fig. 3). In the flanks of steel pinon operating at $80{ }^{\circ} \mathrm{C}$, the polymer transfer film was more distinct and spread across the contact surface compared to pinon running at $50{ }^{\circ} \mathrm{C}$. This is especially true around point E, as seen in Figs. 14 and 15. The overall observation from steel gears thus suggest that only a thin polymer transfer film existed on the gears, similar to findings in tribological tests, and furthermore confirms a more complex contact conditions in realscale gears compared to model tribological tests. 
This peer reviewed manuscript has been accepted for publications to the Wear.

Cite this article as: S. Matkovič, M. Kalin, Effects of slide-to-roll ratio and temperature on the tribological behaviour in polymer-steel contacts and a comparison with the performance of realscale gears, Wear (2021) 477: 203789. DOI: https://doi.org/10.1016/j.wear.2021.203789.

CC BY-NC-ND

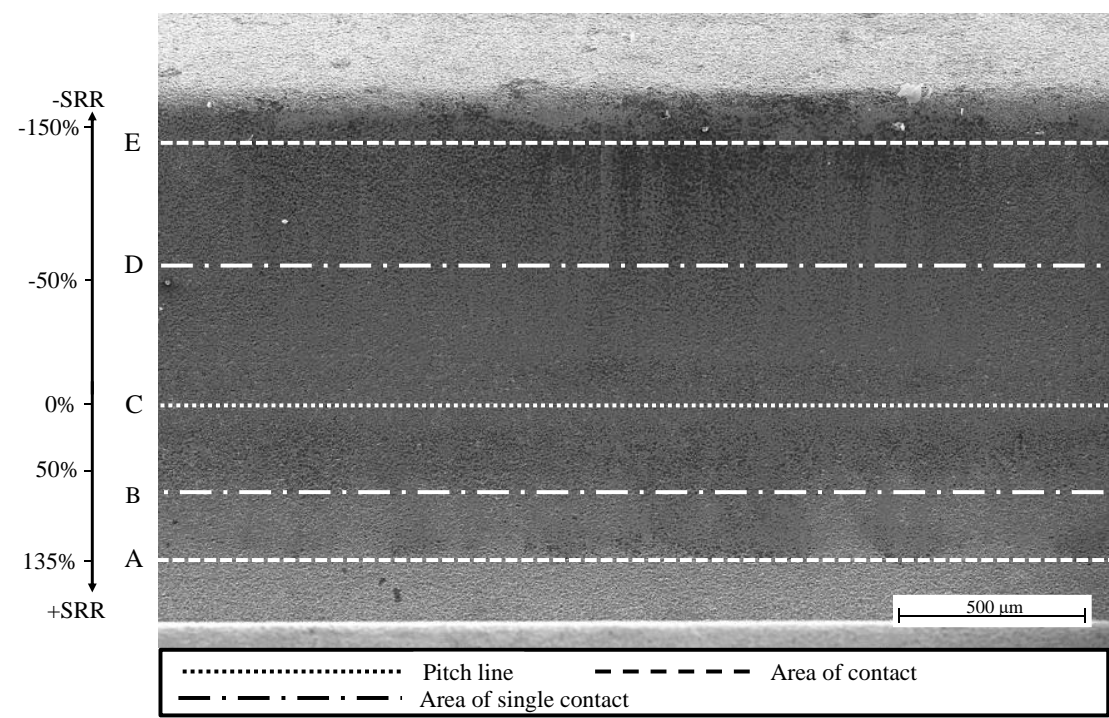

Fig. 14: SEM image of steel pinion that meshed at $50{ }^{\circ} \mathrm{C}$ after 1 million cycles. Characteristic points A-E are shown along the flank with different contact regions.

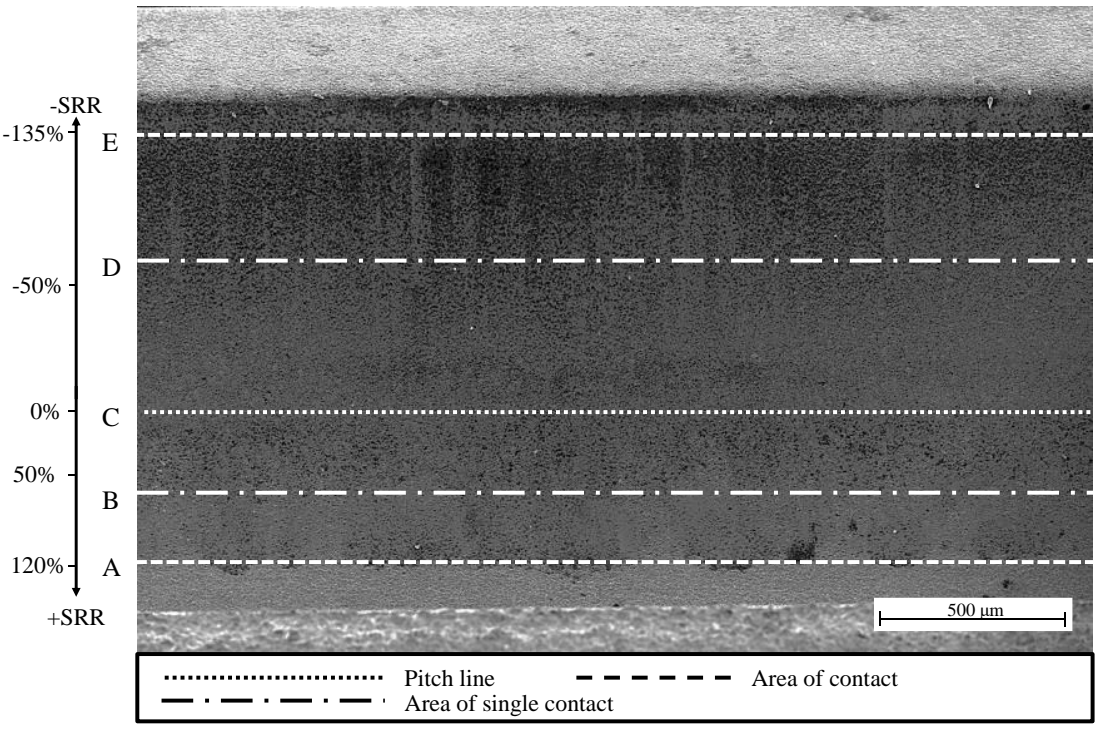

Fig. 15: SEM image of steel pinion that meshed at $80^{\circ} \mathrm{C}$ after 1 million cycles. Characteristic points A-E are shown along the flank with different contact regions. 
This peer reviewed manuscript has been accepted for publications to the Wear.

Cite this article as: S. Matkovič, M. Kalin, Effects of slide-to-roll ratio and temperature on the tribological behaviour in polymer-steel contacts and a comparison with the performance of realscale gears, Wear (2021) 477: 203789. DOI: https://doi.org/10.1016/j.wear.2021.203789.

CC BY-NC-ND

\subsection{Modelling the coefficient of friction on gear flanks from the tribological test data}

Empirical formulations for predicting the coefficient of friction for gears were already proposed by different authors [29-32] following the distribution of the coefficient of friction along the path of contact based on experimental results. However, the proposed models were made for lubricated steel gears. In [33] POM gears were used, but also in this case they were lubricated and not comparable to the dry POM gears in our study. In this work we therefore propose a friction model based on the experimental results measured in SRR-variable model tribological tests, described above.

The proposed model for gear friction combines the effect of the SRR and indirectly the load and temperature from the SRR-variable tribological test, which are all dependent parameters affecting the contact pressure. The FindFit function in Wolfram Mathematica software was used to develop the equation, having the form shown in eq. 7, similar to that already employed in [33].

$\mu(p, S R R)=c_{0}+c_{1} \cdot p+c_{2} \cdot p^{c_{3}} \cdot S R R^{c_{4}}$

(eq. 7)

The coefficients in eq. 7 were resolved based on the measurements of the coefficient of friction on the SRR-variable tribological device. The results from Fig. 4 considering the different SRR values and the mean Hertzian contact pressures under the various tested contact conditions (50/90 MPa at $50{ }^{\circ} \mathrm{C}$ and $30 / 60 \mathrm{MPa}$ at $80{ }^{\circ} \mathrm{C}$, at $8 / 45 \mathrm{~N}$, respectively) were encountered for analyses. The analyses based on the contact conditions described above and the coefficient-of-friction results presented in Fig. 4 led to the empirical friction model, as presented in eq. 8:

$\mu(p, S R R)=0.0577+2.3 \cdot 10^{-4} \cdot p+0.3398 \cdot p^{-0.10553} \cdot S R R^{0.14503}$

The empirical friction model (eq. 8) based on SRR-variable tribological data was used to design the friction curve on the gear flanks from real-scale gear tests, see Fig. 16. The Hertzian pressure along the gear contact path (Fig. 3a) and the SRR values from the gear flanks along the contact path (see Figs. 3,14 and 15 ) at $50{ }^{\circ} \mathrm{C}$ and $80{ }^{\circ} \mathrm{C}$ were employed in eq. 8. Fig. 16, therefore, shows the predicted coefficient of friction along the tested gears in our study.

At the position of pure rolling (position $\mathrm{C}$ ), the friction is around 0.075 , and it was slightly lower for $80^{\circ} \mathrm{C}$. The highest friction values were obtained for positions A (around 0.35) and $\mathrm{E}(0.325)$. Again, these values were slightly higher for the tests at $50{ }^{\circ} \mathrm{C}$ compared to the tests at $80{ }^{\circ} \mathrm{C}$. The 
This peer reviewed manuscript has been accepted for publications to the Wear.

Cite this article as: S. Matkovič, M. Kalin, Effects of slide-to-roll ratio and temperature on the tribological behaviour in polymer-steel contacts and a comparison with the performance of realscale gears, Wear (2021) 477: 203789. DOI: https://doi.org/10.1016/j.wear.2021.203789.

\section{BY-NC-ND}

values are very similar for both temperatures, as can be expected, since the friction model is designed on the basis of tribological experiments, where the friction at the higher temperature of $80{ }^{\circ} \mathrm{C}$ was lower compared to $50{ }^{\circ} \mathrm{C}$.

The gear-friction prediction based on the developed model was compared and verified with the coefficient-of-friction measurements on the real-scale gear test. However, in real-scale gear tests only the average coefficient of friction of the gear pair can be measured (Table 4), so the actual friction distribution along the flank, as predicted in Fig. 16, cannot be verified in our tests. Therefore, we averaged all the data points from the curves in Fig. 16 (separately for both temperatures) and obtained the average predicted gear friction for the gears meshing at $50{ }^{\circ} \mathrm{C}$ of 0.281 and at $80{ }^{\circ} \mathrm{C}$ of 0.280 . These predicted friction values from the friction model (eq. 8) show a surprisingly good match with the experimentally measured friction on the actual real-scale gear tests, which was 0.29 and 0.28 at $50{ }^{\circ} \mathrm{C}$ and $80{ }^{\circ} \mathrm{C}$, respectively. This gives a less than $3 \%$ difference in the friction prediction based on the tribological SRR-variable tests and in an actual real-scale gear test. This validates the use of ball-on-disc tribometers with a variation of the SRR for mimicking and the tribological evaluation of the polymer friction behaviour in gear applications. Although the model is designed from our experimental data, based on such small differences it seems this can serve as a potentially relevant estimation for many other similar cases, as well, since our test conditions are set to common POM/steel gear contacts.

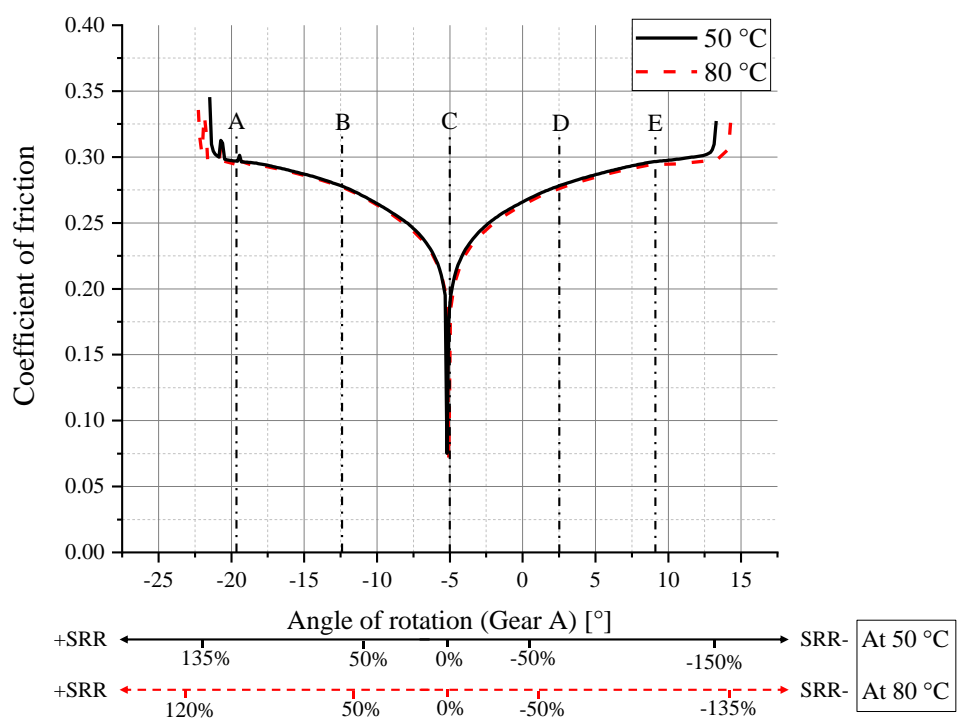

Fig. 16: Predicted gear friction along the gear path of the contact using an empirical model based on tribological tests at $50{ }^{\circ} \mathrm{C}$ and $80{ }^{\circ} \mathrm{C}$. 
This peer reviewed manuscript has been accepted for publications to the Wear.

Cite this article as: S. Matkovič, M. Kalin, Effects of slide-to-roll ratio and temperature on the tribological behaviour in polymer-steel contacts and a comparison with the performance of realscale gears, Wear (2021) 477: 203789. DOI: https://doi.org/10.1016/j.wear.2021.203789.

\section{BY-NC-ND}

\section{Discussion}

This study presents the importance of the SRR on model tribological tests for a realistic evaluation of the tribological behaviour of polymer against steel gears, which is a common combination in more advanced gear applications. The results show the dominant effect of the SRR in model tribological tests, but in close combination with the temperature. The load appears to be a less critical parameter for a low load, while at a high load it obviously enhances the effect of the SRR and the temperature, since the behaviour of the contacts is very different compared to the low load.

The wear behaviour in the tests with a tribometer having a variable SRR was very much dependent on the SRR (Fig. 6), but in a close relation with the temperature, i.e., the wear mechanisms observed at $50{ }^{\circ} \mathrm{C}$ and $80{ }^{\circ} \mathrm{C}$ were very different. However, at both temperatures the wear monotonically increased with the SRR and the wear coefficient was even of the same order of $10^{-}$ ${ }^{5} \mathrm{~mm}^{3} /(\mathrm{Nm})$. But, it is important to note that the model tribometer tests were able to distinguish the different wear mechanisms depending on the SRR and the temperature, confirming our initial hypothesis about the importance of the SRR in the model tribological test for gear applications. While for a low SRR the wear mechanisms were similar at $50{ }^{\circ} \mathrm{C}$ and $80{ }^{\circ} \mathrm{C}$ (Fig. 7), with an increase to $100 \%$ SRR and even more to $150 \%$ SRR, there was a complete change in the wear mechanism. The mechanism at high SRR thus also depended on the temperature (Figs. 8 and 9). At $50{ }^{\circ} \mathrm{C}$ the wear mechanism is mechanically driven with some plastic deformation in the form of ridges. At $80{ }^{\circ} \mathrm{C}$, in contrast, the surfaces were completely thermally deformed and melted to give a non-recognisable wear mechanism, making it impossible to have any detailed wearmechanism comparison and analyses. This, however, resulted in lower wear (Figs. 5 and 6), since the wear debris are generated at a slower rate in such a case.

When we compare the model tribometer tests with the real-scale gear tests, we observe a clear similarity for some conditions between the tribological results and the gear behaviour, but not for all. For example, similar to the tribological tests, the wear of the gears at $50{ }^{\circ} \mathrm{C}$ was also higher than at $80{ }^{\circ} \mathrm{C}$ (Table 4). On the other hand, the $50{ }^{\circ} \mathrm{C}$ tribological test mimics the gear tests of both $50{ }^{\circ} \mathrm{C}$ and $80{ }^{\circ} \mathrm{C}$ much more closely. In the gear tests at $50{ }^{\circ} \mathrm{C}$ and $80{ }^{\circ} \mathrm{C}$ we observe in the $\mathrm{B}-\mathrm{C}$ and $\mathrm{C}-\mathrm{D}$ regions, exactly the same worn surface features in the form of ridges as in the $50{ }^{\circ} \mathrm{C}$ model tribological test for the same (or very similar) SRR values. Thus, at both temperatures the gear wear was mostly mechanically driven through deformation of the surface layer - similar to the $50{ }^{\circ} \mathrm{C}$ test in the model tribological tests, see Figs. 8 and 9. For the gear tests at the high temperature of $80{ }^{\circ} \mathrm{C}$ these sliding regions in the gears shifted and enlarged slightly, which is discussed and explained later on, but the main mechanically driven mechanism is maintained.

Another obvious (and expected) piece of information from the gear tests is that the wear mechanisms change in the different sliding regions along the flank, see Figs. 12 and 13. In summary, the following three wear behaviours along the flanks at different sliding regions can be clearly distinguished: (i) a high-wear region in the $\mathrm{B}-\mathrm{C} / \mathrm{C}-\mathrm{D}$ position, where the deformation 
This peer reviewed manuscript has been accepted for publications to the Wear.

Cite this article as: S. Matkovič, M. Kalin, Effects of slide-to-roll ratio and temperature on the tribological behaviour in polymer-steel contacts and a comparison with the performance of realscale gears, Wear (2021) 477: 203789. DOI: https://doi.org/10.1016/j.wear.2021.203789.

CC BY-NC-ND

ridges were located in the area of the single-tooth contact, where the pressure was highest, similar to earlier findings [21]; (ii) the pitch-line region (position $\mathrm{C}$ ), where only rolling motion was present and the possible initiation of fatigue features due to high pressures; and (iii) the A-B/D-E region in the double-tooth contact, where the pressures were low, while the SRR was very high, leading to severe sliding with some abrasive wear in the form of scratches.

It is thus clear that the gear flanks tested at $50{ }^{\circ} \mathrm{C}$ with about $50-150 \%$ SRR experience the same deformation ridges as in the $50{ }^{\circ} \mathrm{C}$ tribological tests for the same SRR and high load, while for the $0-50 \%$ SRR and low load, the ridges on the gear diminished, to give extremely low wear of any kind at around 0\% SRR. Exactly the same as was found in tribological tests: at low SRR values and low load, there were no ridges (Fig. 7), while at high load and SRR (Fig. 8 and 9), they were clearly observed. This shows that the tribotest with a variation of SRR closely mimics the different wear mechanisms and realistically simulates the wear behaviour along the gear flanks at $50{ }^{\circ} \mathrm{C}$.

The gear test at $80{ }^{\circ} \mathrm{C}$ showed very similar wear behaviour to the $50{ }^{\circ} \mathrm{C}$ gear test; however, the sliding regions along the flanks were not theoretically correct anymore. They were extended over the theoretical borders, and the total contact length was prolonged, see Fig. 13. This is a clear indication that due to the increased thermal load the gear teeth deformed and extended under the compressive and bending stress. Moreover, due to the reduced mechanical properties of the polymer, the contact Hertzian stress reduced and so the wear was also reduced, see Table 4. It should be noted that the POM's modulus of elasticity at $80{ }^{\circ} \mathrm{C}$ is almost $60 \%$ smaller than at $50{ }^{\circ} \mathrm{C}$. Thus, in spite of the fact that the wear mechanism under these conditions was still predominately mechanical, it is obvious that the thermal stress is increasing and approaching the transition to thermal wear, but was not yet achieved under these conditions.

This was, however, experienced in the model tribometer tests conducted at $80{ }^{\circ} \mathrm{C}$, where this transition was effective entirely - and so did not mimic the gear tests. Obviously, the $80{ }^{\circ} \mathrm{C}$ model tribometer tests represent much more severe contact conditions due to more intense contact without cooling, while the gears can still partially cool due to the significant speed and entry of fresh air.

It should be noted that in common pin-on-disc tests with pure sliding (200\% SRR), for increased contact severity, the worn surfaces often suddenly change from mechanical wear with common wear mechanisms to severe thermal degradation, not allowing any detailed analyses and specifics or gradients of the wear behaviour, thus losing many details of the wear behaviour [34]. This is due to the too intense and thermally loaded contacts. However, as seen in this study, the SRR variations in the model tribological tests can provide much more details and compensate for the typically required high stress with severe mechanism transitions.

Accordingly, the gear-wear mechanisms can be very nicely captured with model tribological tests using a variable SRR and load, although the wear coefficient is about one order of magnitude higher in the tribological tests. However, it should be noted that in the conventional pin-on-disc 
This peer reviewed manuscript has been accepted for publications to the Wear.

Cite this article as: S. Matkovič, M. Kalin, Effects of slide-to-roll ratio and temperature on the tribological behaviour in polymer-steel contacts and a comparison with the performance of realscale gears, Wear (2021) 477: 203789. DOI: https://doi.org/10.1016/j.wear.2021.203789.

\section{BY-NC-ND}

tests, the wear-coefficient difference compared to the gears is typically $2-4$ orders of magnitude $[13,14,35]$, and thus much less comparable to the gears than in the present tribological tests with the SRR variation. Moreover, in our tribological tests the wear at $50{ }^{\circ} \mathrm{C}$ and $80{ }^{\circ} \mathrm{C}$ was of the same order of magnitude, which confirms the relevance of these model tribotests, even at different temperatures.

However, it appears obvious that high-temperature model tests (e.g., $80{ }^{\circ} \mathrm{C}$ ) result in a too high thermal load on the model tribological samples, which are not able to cool down, so the realism of gear's contact conditions at such a high temperature is lost. We suggest that for wear analyses and wear-mechanism studies of POM gears at around or above $80{ }^{\circ} \mathrm{C}$, a few tens of ${ }^{\circ} \mathrm{C}$ lower tribological tests with a variable SRR are performed, to maintain the realistic mechanisms. In this way we can expect from the model tribological tests an about 10-times-higher wear coefficient, but the same wear mechanisms.

The friction results in the model tribometer test are even more obviously dependent on the SRR (Fig. 4). At both 50 and $80{ }^{\circ} \mathrm{C}$, the friction rapidly increases from pure rolling (0\% SRR) to even slight sliding. Already at low SRR values $(25 \%)$ the coefficient of friction reaches its average value of about 0.25 . This value remains relatively constant for all the low-SRR region. However, exceeding $75 \%$ SRR for the low temperature and 125\% SRR for the high temperature, the friction starts do deviate significantly. At low load it further increases, while at high load it decreases. At $150 \%$ SRR this difference is already about $21 \%$, reaching 0.33 for the $8 \mathrm{~N}$ test and 0.26 for $45 \mathrm{~N}$. Our SRR-variable tribometer was not able to achieve higher SRR values than $150 \%$ with polymer balls, but these results show that when approaching 200\% SRR, which is the pure sliding in common pin-on-disc experiments, the friction will be notably different and highly dependent on the load, in addition to the SRR, as shown before. This agrees with the literature data where the friction values for the POM can indeed be anywhere between 0.01 and $0.7[14,15,35,36]$.

However, the average coefficient of friction in the gear tests shows a surprisingly good similarity with the coefficient of friction measured with the SRR-variable tribometer in the region 50-100\% SRR or even $125 \%$ SRR. This similarity was observed for both studied temperatures, $50{ }^{\circ} \mathrm{C}$ and $80^{\circ} \mathrm{C}$. Accordingly, the SRR-variable tribometer can mimic extremely well the average friction conditions in the gears. It must be emphasised here that SRR changes along the gear flanks, and so does the coefficient of friction. Accordingly, in gears, it is not possible to measure the exact friction along the contact position on the gear flank, but only the average gear-pair friction.

For this reason we developed a model that can predict the friction values along the flanks based on tribological tests with a variable SRR, as given in eq. 8. The comparison of the average coefficient of friction along the contact path calculated with the model and measurements on the gears shows an extremely good match, with a difference of only $3 \%$, which verifies the model for the conditions used. It is believed that due to the low uncertainty and the verification via the wear 
This peer reviewed manuscript has been accepted for publications to the Wear.

Cite this article as: S. Matkovič, M. Kalin, Effects of slide-to-roll ratio and temperature on the tribological behaviour in polymer-steel contacts and a comparison with the performance of realscale gears, Wear (2021) 477: 203789. DOI: https://doi.org/10.1016/j.wear.2021.203789.

CC BY-NC-ND

mechanisms, the applicability of the model can be extended from these exact parameters, and still obtain relevant details about the friction of the gear pair.

One last interesting phenomena observed in this work relates to polymer transfer film on the steel samples. In the model tribological tests and gear tests, there was always some transfer film formed, however, the harder steel samples did not scratch-off the polymer severely and the abrasive action was not dominating the tribological behaviour. In fact, the transfer film was quite thin in both, model tribological tests and gear tests, and was more smeared with higher temperature. More variation of the polymer transfer film was observed in gears, where the presence and coverage of the film varied along the flanks. However, due to the low thickness the film did not introduce significant thermal aspects, as can be concluded from friction and wear behaviours at the two temperatures and it does not appear to affect the general observations and the differences between the model tribological and the gear tests in this work.

To summarise, the variation in SRR is crucial for the model tribological test. The SRR-variable tribological tests thus show much better predictive power for real polymer-gear tests compared to the common pure sliding tribological tests. Firstly, the wear coefficient is only one order of magnitude higher, compared to the gear tests, while the common pin-on-disc tests are 2-4 orders away $[13,14,35]$. Secondly, the wear mechanisms in a SRR-variable tribometer can almost exactly mimic the wear mechanism in different sliding regions along the gear flanks, which is impossible with pin-on-disc, thus giving an improved understanding and reliability of the predictions. Moreover, common pin-on-disc tests, after exceeding some contact severity, suddenly reach complete thermal degradation of the material and lose relevant wear-behaviour details. In the SRRvariable tribometer, SRR replaces the severity on account of the contact pressure, which changes significantly in pin-on-disc tests due to the ball (pin) wear and so changes the sliding conditions. Moreover, by rotating the polymer ball, the surface experiences more similar conditions to the gears vs. the pin-on-disc, where the polymer pin is always in the contact and exceeding the realistic temperature. Even in the SRR-variable tester, this is not an "ideal" contact, but nevertheless, it brings many qualitative and even orders-of-magnitude-better quantitative results. Finally, and in contrast to some remaining deficiencies in the wear analyses from the model tribological tests, the friction behaviour and the values can be very accurately predicted in the proposed friction model based on the results obtained on the SRR-variable tribometer tests. The predicted coefficient of friction can then be used with other models, such as [4,27] or similar, to predict the temperature on the gear flanks, or to be used in further detailed gear-behaviour predictions and simulations. 
This peer reviewed manuscript has been accepted for publications to the Wear.

Cite this article as: S. Matkovič, M. Kalin, Effects of slide-to-roll ratio and temperature on the tribological behaviour in polymer-steel contacts and a comparison with the performance of realscale gears, Wear (2021) 477: 203789. DOI: https://doi.org/10.1016/j.wear.2021.203789.

\section{BY-NC-ND}

\section{Conclusions}

1. SRR variations have a crucial effect on the wear and friction behaviour of polymer/steel in model tribological tests. In contrast to conventional pin-on-disc tests with pure sliding, the variation of SRR in the model tribological test is able to mimic different wear mechanisms along the real-gear-meshing path, which is characteristic for different SRR values.

2. The $50{ }^{\circ} \mathrm{C}$ model test with the SRR variation can simulate the wear behaviour in real gears at $50{ }^{\circ} \mathrm{C}$ very accurately, which is not possible with a conventional pin-on-disc. With some critical appraisal and extrapolation, these results can be extended to $80{ }^{\circ} \mathrm{C}$ real-gear tests. In contrast, the $80{ }^{\circ} \mathrm{C}$ model tribotests are too severe and lead to thermal degradation of the material and lose relevant wear-behaviour details.

3. Wear in both the SRR-variable model tribotests and the gear test was larger at $50{ }^{\circ} \mathrm{C}$ than at $80{ }^{\circ} \mathrm{C}$, where the transition in the wear mechanisms from mechanical to thermal dominance occur.

4. An about one-order-of-magnitude-larger wear coefficient is obtained in the SRR-variable model test compared to the real-gear tests, which is significantly better than the common 2-4 orders variations in conventional pin-on-disc tests with pure sliding.

5. Friction is also highly dependent on the SRR. From very low $(25 \%)$ to intermediate SRR values (about $100 \%$ ) the friction is about the same, i.e., $\sim 0.3$ for all contact conditions. At high SRR values and low load the friction increases and approaches $\sim 0.35$, while at high load it decreases towards $\sim 0.25$, i.e., a $30 \%$ variation of friction at $150 \%$ SRR. This suggests even larger differences under typical pure sliding in pin-disc tests (i.e., at 200\%, not measured in this study), which are not present for realistic SRR values in gears.

6. The coefficient of friction measured with the SRR-variable tribometer in the region of 50$125 \%$ SRR mimics the average coefficient of friction in real-gear tests extremely well at all temperatures and loads.

7. A predictive model for the friction along the meshing line on the gear flanks based on tribological tests with variable SRR was developed that has only 3\% deviation compared to average coefficient of friction measured on real gears. The model is relevant for many contact conditions in polymer/steel contacts.

\section{Declaration of competing interest}

The authors declare that they have no known competing financial interests or personal relationships that could have appeared to influence the work reported in this paper.

\section{Acknowledgment}

The authors acknowledge the financial support from the Slovenian Research Agency, Slovenia (research core funding No. P2-0231). 
This peer reviewed manuscript has been accepted for publications to the Wear.

Cite this article as: S. Matkovič, M. Kalin, Effects of slide-to-roll ratio and temperature on the tribological behaviour in polymer-steel contacts and a comparison with the performance of realscale gears, Wear (2021) 477: 203789. DOI: https://doi.org/10.1016/j.wear.2021.203789.

\section{BY-NC-ND}

\section{References}

[1] A.K. Singh, P.K. Singh, Polymer spur gears behaviors under different loading conditions: A review, Proc. Inst. Mech. Eng. Part J J. Eng. Tribol. 232 (2018) 1-19. https://doi.org/10.1177/1350650117711595.

[2] S. Fakirov, Fundamentals of Polymer Science for Engineers, Wiley-VCH Verlag GmbH \& Co. KGaA, Weinheim, Germany, 2017. https://doi.org/10.1002/9783527802180.

[3] T.A. Osswald, G. Menges, Material Science of Polymers for Engineers, 2012. https://doi.org/10.3139/9781569905241.fm.

[4] K. Mao, A numerical method for polymer composite gear flash temperature prediction, Wear. 262 (2007) 1321-1329. https://doi.org/10.1016/j.wear.2007.01.008.

[5] A. Pogačnik, J. Tavčar, An accelerated multilevel test and design procedure for polymer gears, Mater. Des. 65 (2015) 961-973. https://doi.org/10.1016/J.MATDES.2014.10.016.

[6] S.P. Radzevich, Theory of gearing: Kinematics, geometry, and synthesis, CRC Press, 2012. https://doi.org/10.1201/b12727.

[7] M. Harrass, K. Friedrich, A.A. Almajid, Tribological behavior of selected engineering polymers under rolling contact, Tribol. Int. 43 (2010) 635-646. https://doi.org/10.1016/J.TRIBOINT.2009.10.003.

[8] K. Friedrich, Polymer composites for tribological applications, Adv. Ind. Eng. Polym. Res. 1 (2018) 3-39. https://doi.org/10.1016/j.aiepr.2018.05.001.

[9] M. Zalaznik, M. Kalin, S. Novak, G. Jak, Effect of the type, size and concentration of solid lubricants on the tribological properties of the polymer PEEK, 365 (2016) 31-39. https://doi.org/10.1016/j.wear.2016.06.013.

[10] M. Kalin, M. Zalaznik, S. Novak, Wear and friction behaviour of poly-ether-ether-ketone (PEEK) filled with graphene, WS 2 and CNT nanoparticles, 333 (2015) 855-862. https://doi.org/10.1016/j.wear.2014.12.036.

[11] M. Zalaznik, M. Kalin, S. Novak, Influence of the processing temperature on the tribological and mechanical properties of poly-ether-ether-ketone (PEEK) polymer, Tribol. Int. 94 (2016) 92-97. https://doi.org/10.1016/j.triboint.2015.08.016.

[12] A. Pogačnik, M. Kalin, Parameters influencing the running-in and long-term tribological behaviour of polyamide (PA) against polyacetal (POM) and steel, Wear. 290-291 (2012) 140-148. https://doi.org/10.1016/j.wear.2012.04.017. 
This peer reviewed manuscript has been accepted for publications to the Wear.

Cite this article as: S. Matkovič, M. Kalin, Effects of slide-to-roll ratio and temperature on the tribological behaviour in polymer-steel contacts and a comparison with the performance of realscale gears, Wear (2021) 477: 203789. DOI: https://doi.org/10.1016/j.wear.2021.203789.

\section{BY-NC-ND}

[13] A. Pogačnik, Vpliv fizikalnih parametrov na tribološke lastnosti polimerov za zobnike: Doktorska disertacija, Univerza v Ljubljani, 2013.

[14] H. Unal, U. Sen, A. Mimaroglu, Dry sliding wear characteristics of some industrial polymers against steel counterface, Tribol. Int. 37 (2004) 727-732. https://doi.org/10.1016/J.TRIBOINT.2004.03.002.

[15] S. Odi-Owei, D.J. Schipper, Tribological behaviour of unfilled and composite polyoxymethylene, Wear. 148 (1991) 363-376. https://doi.org/10.1016/00431648(91)90295-6.

[16] J. Sukumaran, M. Ando, P. De Baets, V. Rodriguez, L. Szabadi, G. Kalacska, V. Paepegem, Modelling gear contact with twin-disc setup, Tribol. Int. 49 (2012) 1-7. https://doi.org/10.1016/j.triboint.2011.12.007.

[17] Y.K. Chen, O.P. Modi, A.S. Mhay, A. Chrysanthou, J.M. O'Sullivan, The effect of different metallic counterface materials and different surface treatments on the wear and friction of polyamide 66 and its composite in rolling-sliding contact, Wear. 255 (2003) 714-721. https://doi.org/10.1016/S0043-1648(03)00054-1.

[18] D.H. Gordon, S.N. Kukureka, The wear and friction of polyamide 46 and polyamide 46/aramid-fibre composites in sliding-rolling contact, Wear. 267 (2009) 669-678. https://doi.org/10.1016/j.wear.2008.11.026.

[19] S.N. Kukureka, Y.K. Chen, C.J. Hooke, P. Liao, The wear mechanisms of acetal in unlubricated rolling-sliding contact, Wear. 185 (1995) 1-8. https://doi.org/10.1016/00431648(94)06575-6.

[20] T.J. Hoskins, K.D. Dearn, Y.K. Chen, S.N. Kukureka, The wear of PEEK in rolling-sliding contact - Simulation of polymer gear applications, Wear. 309 (2014) 35-42. https://doi.org/10.1016/j.wear.2013.09.014.

[21] S.M. Evans, P.S. Keogh, Wear mechanisms in polyoxymethylene spur gears, Wear. 428429 (2019) 356-365. https://doi.org/10.1016/j.wear.2019.03.027.

[22] M. Björling, J. Miettinen, P. Marklund, A. Lehtovaara, R. Larsson, The correlation between gear contact friction and ball on disc friction measurements, Tribol. Int. 83 (2015) 114-119. https://doi.org/10.1016/j.triboint.2014.11.007.

[23] M. Kalin, A. Kupec, The dominant effect of temperature on the fatigue behaviour of polymer gears, Wear. 376-377 (2017) 1339-1346. https://doi.org/10.1016/j.wear.2017.02.003.

[24] ISO 1328:2013 Cylindrical gears — ISO system of flank tolerance classification, 2013.

[25] DuPont, Delrin ® acetal resins: design infromation, (2013).

[26] Kiss. AG, KISSsoft, (n.d.). https://old.kisssoft.ag/Manual/en/index.htm (accessed 
This peer reviewed manuscript has been accepted for publications to the Wear.

Cite this article as: S. Matkovič, M. Kalin, Effects of slide-to-roll ratio and temperature on the tribological behaviour in polymer-steel contacts and a comparison with the performance of realscale gears, Wear (2021) 477: 203789. DOI: https://doi.org/10.1016/j.wear.2021.203789.

\section{BY-NC-ND}

September 1, 2020).

[27] VDI 2736: Thermoplastic gear wheels. VDI Richtlinien. Dusseldorf: VDI-Verlag GmbG; 2014, 2014.

[28] W. C, K. Banaschek, FVA-Bericht 129 und 134, Elastische Formänderung der Zähne und der anschliessenden Teile der Radkörper von Zahnradgetrieben, FVA. (1955).

[29] L. Schlenk, Untersuchungen zur Freßtragfähigkeit von Großzahnrädern PhD Thesis, Technical University Munich, 1995. https://mediatum.ub.tum.de/doc/1355983/file.pdf (accessed October 6, 2020).

[30] H. Xu, Development of a generalized mechanical efficiency prediction methodology for $\begin{array}{llll}\text { gear } & \text { Ohirs, State } & & \\ \end{array}$ https://etd.ohiolink.edu/pg_10?0::NO:10:P10_ACCESSION_NUM:osu1128372109 (accessed October 6, 2020).

[31] K. Michaelis, B.R. Höhn, Influence of lubricants on power loss of cylindrical gears, Tribol. Trans. 37 (1994) 161-167. https://doi.org/10.1080/10402009408983279.

[32] P.M.T. Marques, R.C. Martins, J.H.O. Seabra, Power loss and load distribution models including frictional effects for spur and helical gears, Mech. Mach. Theory. 96 (2016) 125. https://doi.org/10.1016/j.mechmachtheory.2015.09.005.

[33] D. Miler, M. Hoić, Z. Domitran, D. Žeželj, Prediction of friction coefficient in drylubricated polyoxymethylene spur gear pairs, Mech. Mach. Theory. 138 (2019) 205-222. https://doi.org/10.1016/J.MECHMACHTHEORY.2019.03.040.

[34] A. Pogačnik, A. Kupec, M. Kalin, Tribological properties of polyamide (PA6) in self-mated contacts and against steel as a stationary and moving body, Wear. 378-379 (2017) 17-26. https://doi.org/10.1016/j.wear.2017.01.118.

[35] H. Unal, A. Mimaroglu, Influence of test conditions on the tribological properties of $\begin{array}{lllll}\text { polymers, Ind. } & \text { Lubr. } & \text { Tribol. } & 55 & \text { (2003) 178-183. }\end{array}$ https://doi.org/10.1108/00368790310480362.

[36] H. Unal, A. Mimaroglu, Friction and wear behaviour of unfilled engineering thermoplastics, Mater. Des. 24 (2003) 183-187. https://doi.org/10.1016/S0261-3069(03)00018-9. 